\title{
Calprotectin-mediated zinc chelation inhibits Pseudomonas aeruginosa protease activity in cystic fibrosis sputum
}

Danielle M. Vermilyea ${ }^{a}$, Alex W. Crocker ${ }^{a}$, Alex H. Gifford ${ }^{b, c}$, and Deborah A. Hogan ${ }^{a, \#}$

${ }^{a}$ Geisel School of Medicine at Dartmouth, Hanover, New Hampshire

b Pulmonary and Critical Care Medicine, Dartmouth-Hitchcock Medical Center, Lebanon, New Hampshire

c The Dartmouth Institute for Health Policy and Clinical Practice, Lebanon, New Hampshire

Running title: Calprotectin inhibits $P$. aeruginosa proteases

\# Address correspondence to:

Department of Microbiology and Immunology

Geisel School of Medicine at Dartmouth

Rm 208 Vail Building

Hanover, NH 03755

E-mail: dhogan@dartmouth.edu

Tel: (603) 650-1252 


\section{Abstract}

Pseudomonas aeruginosa induces pathways indicative of low zinc availability in the cystic

3 fibrosis (CF) lung environment. To learn more about $P$. aeruginosa zinc access in CF, we grew

4 P. aeruginosa strain PAO1 directly in expectorated CF sputum. The P. aeruginosa Zur

5 transcriptional repressor controls the response to low intracellular zinc, and we used the

6 NanoString methodology to monitor levels of Zur-regulated transcripts including those encoding

7 a zincophore system, a zinc importer, and paralogs of zinc containing proteins that do not require

8 zinc for activity. Zur-controlled transcripts were induced in sputum-grown $P$. aeruginosa compared

9 to control cultures, but not if the sputum was amended with zinc. Amendment of sputum with

10 ferrous iron did not reduce expression of Zur-regulated genes. A reporter fusion to a Zur-regulated

11 promoter had variable activity in $P$. aeruginosa grown in sputum from different donors, and this

12 variation inversely correlated with sputum zinc concentrations. Recombinant human calprotectin

13 (CP), a divalent-metal binding protein released by neutrophils, was sufficient to induce a zinc-

14 starvation response in $P$. aeruginosa grown in laboratory medium or zinc-amended CF sputum

15 indicating that $\mathrm{CP}$ is functional in the sputum environment. Zinc metalloproteases comprise a

16 large fraction of secreted zinc-binding $P$. aeruginosa proteins. Here we show that recombinant

17 CP inhibited both LasB-mediated casein degradation and LasA-mediated lysis of Staphylococcus

18 aureus, which was reversible with added zinc. These studies reveal the potential for CP-mediated

19 zinc chelation to post-translationally inhibit zinc metalloprotease activity and thereby impact the

20 protease-dependent physiology and/or virulence of $P$. aeruginosa in the CF lung environment. 
bioRxiv preprint doi: https://doi.org/10.1101/2021.02 25.432981· this version posted March 1, 2021. The copyright holder for this preprint

(which was not certified by peer review) is the author/funder, who has granted bioRxiv a license to display the preprint in perpetuity. It is made available under aCC-BY-NC 4.0 International license.

\section{Importance}

The factors that contribute to worse outcomes in individuals with cystic fibrosis (CF) with

23 chronic Pseudomonas aeruginosa infections are not well understood. Therefore, there is a need

24 to understand environmental factors within the CF airway that contribute to $P$. aeruginosa

25 colonization and infection. We demonstrate that growing bacteria in CF sputum induces a zinc-

26 starvation response that inversely correlates with sputum zinc levels. Additionally, both

27 calprotectin and a chemical zinc chelator inhibit the proteolytic activities of LasA and LasB

28 proteases suggesting that extracellular zinc chelators can influence proteolytic activity and thus

$29 P$. aeruginosa virulence and nutrient acquisition in vivo. 


\section{Introduction}

In cystic fibrosis (CF), microbes such as Pseudomonas aeruginosa colonize airway mucus

32 where they then compete with host cells and other microbes for nutrients, including metals.

33 Divalent metal ions (e.g., $\mathrm{Zn}^{2+}, \mathrm{Fe}^{2+}, \mathrm{Mn}^{2+}$, etc.) are essential micronutrients for host and microbe

34 alike, in part, because they act as cofactors in enzymes important for a variety of cellular functions.

35 While the concentration of metals, such as zinc, in CF sputum can vary, the concentration of zinc

36 in expectorated sputum from CF patients is elevated, on average, compared to levels in samples

37 from healthy controls (1-3). However, studies investigating the transcriptional response of $P$.

38 aeruginosa in CF sputum show that a common gene expression pattern is the increased expression of zinc uptake and transport genes (4-9), which are normally expressed when zinc is limited. The $P$. aeruginosa zinc-starvation response is regulated by the zinc uptake regulator

41 (Zur), which is a transcriptional repressor (10). When intracellular zinc is high, Zur monomers bind

42 zinc, dimerize, and bind DNA to repress gene expression of zinc uptake pathways. When

43 intracellular zinc becomes low, the dimeric, zinc-bound fraction of Zur decreases, which leads to

44 derepression of genes involved in zinc uptake and the expression of zinc-free paralogs of essential proteins (zinc-sparing response). The $P$. aeruginosa Zur regulon $(11,12)$ includes the

46 zinc transporter-encoding operon $\operatorname{znuABCD}(10,13,14)$, the zincophore-encoding operon

47 cntILMO $(15,16)$, and zinc-free paralogs of ribosomal proteins (PA3600 and PA3601) $(13,17)$

48 and transcription factors ( $d k s A 2)$ (18). These responses not only reduce the requirement for zinc

49 but liberate the zinc that was stored in the zinc-dependent forms of these proteins (19).

50 The host, on the other hand, utilizes nutritional immunity to sequester metal ions away

51 from pathogens to reduce bacterial growth and control infection (20). One of the most abundant

52 zinc-binding host proteins in CF is calprotectin (CP), which was previously named "the cystic

53 fibrosis antigen" because of its abundance in the serum, sputum, and bronchoalveolar lavage

54 fluid (BALF) of individuals with CF $(2,21-24)$. Neutrophils recruited to sites of inflammation release

$55 \mathrm{CP}$ as S100A8/A9 heterodimers $(25,26)$, which then form tetramers in environments with 
56 sufficient levels of calcium $(27,28)$. Each heterodimer has two divalent-metal binding sites: one

57 site has high affinity for zinc and low affinity for manganese while the other site is capable of

58 binding divalent manganese, iron, zinc, or nickel (29). CP is thought to induce zinc limitation as a

59 means to control infections caused by Staphylococcus aureus, Acinetobacter baumannii in

60 tissues, and Salmonella enterica serovar Typhimurium in the gastrointestinal tract (30-32).

61 However, little is known about the effect of CP-mediated zinc sequestration on $P$. aeruginosa

62 growth and physiology.

63 Additionally, CP has been shown to inhibit the activity of metalloproteases such as host

64 matrix metalloproteinases via zinc chelation (33). P. aeruginosa regulates expression of several

65 metalloenzymes, including zinc metalloproteases, by quorum sensing (QS), which is a

66 mechanism that regulates gene expression in accordance with cell density through the secretion

67 of signal molecules. The secretion of zinc metalloproteases LasB (PA3724), LasA (PA1871), AprA

68 (PA1249), ImpA (PA0572), PepB (PA2939), and Protease IV (PA4175) (Table 1) are regulated

69 by transcriptional regulators LasR and RhIR involved in QS $(34,35)$. This coordinated expression

70 may be of particular importance for optimal protease activity given recent findings showing that

71 LasB, Protease IV, and LasA are activated after being secreted by a QS-induced proteolytic

72 cascade in which LasB activates Protease IV and then Protease IV, in turn, activates LasA (36,

73 37). Expression of these zinc metalloproteases is important for $P$. aeruginosa colonization and

74 virulence because they play key roles in processes such as degrading host proteins (e.g., elastin)

75 (38), invading host cells (39), evading host immune responses (40-42), and lysing other bacteria

76 (e.g., S. aureus) $(43,44)$. While incubation of $P$. aeruginosa zinc metalloproteases with chemical

77 zinc chelators inhibits their activity $(45,46)$, the effect of physiologically relevant zinc chelators

78 such as CP on the activity of $P$. aeruginosa zinc metalloproteases remains unclear.

To test these hypotheses, we used a novel method in which $P$. aeruginosa strain PAO1

80 was grown directly in unamended expectorated CF sputum and matched sputum samples treated

81 with divalent metals (e.g., $\mathrm{Zn}^{2+}$ and $\mathrm{Fe}^{2+}$ ) and zinc chelators (e.g., TPEN and CP). The effect of 
82 zinc chelators on $P$. aeruginosa zinc metalloprotease activity was further assessed using

83 protease-specific assays. Overall, our findings support a model in which zinc chelation by CP in

84 the mucus of the CF lung may impact the ecology of colonizing $P$. aeruginosa by inhibiting the 85 activity of proteases involved in processes such as nutrient acquisition and interspecies 86 competition.

\section{Results}

$P$. aeruginosa exhibits a Zur-regulated zinc-starvation response when grown in CF sputum samples from different donors genes in CF sputum (4-6), we first constructed a lacZ fusion to the promoter of PA3600 on the chromosome of $P$. aeruginosa strain PAO1 (PAO1 att:: $\mathrm{P}_{P A 3600}-l a c Z$ ) to act as a tool to explore factors that influence the activation of the Zur regulon. PA3600 encodes the Zur-regulated zinc-

97 (LB), medium containing TPEN ( $N, N, N^{\prime}, N^{\prime}$-tetrakis-2-pyridylmethyl-ethylenediamine), or medium containing both TPEN and zinc (Fig. 1a). TPEN is a membrane permeable metal ion chelator with a high affinity for zinc (47) and was therefore used to induce a zinc-starvation response in $P$. aeruginosa. P. aeruginosa grown for $3 \mathrm{~h}$ in LB had little promoter activity ( 23 Miller Units [MU]),

101 while growth in medium containing TPEN resulted in a seven-fold increase in promoter activity 102 ( 150 MU) (Fig. 1a). The addition of TPEN and an excess of zinc $(1 \mathrm{mM})$ did not stimulate 103 promoter activity (Fig. 1a). The ability of sputum to activate the PA3600 promoter was then 104 determined by growing $P$. aeruginosa in M63 minimal medium containing $0.2 \%$ glucose (M63), 105 culture medium plus TPEN (positive control), or expectorated CF sputum from 10 different donors 106 (Fig. 1b). While $P$. aeruginosa grown for $3 \mathrm{~h}$ in M63 exhibited greater promoter activity ( 85 MU) 107 than when grown in LB ( $23 \mathrm{MU})$, growth in CF sputum resulted in a three-fold increase in 
promoter activity ( 281 MU). Average promoter activation in CF sputum was statistically the same as promoter activity induced by TPEN (Fig. 1b).

111 expression of PA3600 and three additional Zur-regulated genes. To do so, we used NanoString

112 technology, which is a hybridization-based method that is quantitative, not hindered by

113 contaminating DNA in sputum, and requires only a small amount of RNA. Consequently,

114 NanoString works well for the analysis of small clinical sample aliquots (e.g., sputum) as

115 previously demonstrated $(48,49)$. In this study, NanoString technology allowed for the analysis

116 of subset of Zur-regulated genes: PA3600, cntO, znuA, and dksA2. Analysis showed an induction

117 of these Zur-regulated genes in P. aeruginosa grown in sputum compared to M63 (Fig. 1c).

118 Amending samples with excess zinc $(1 \mathrm{mM})$ was sufficient to reduce the expression of Zur-

119 regulated genes (Fig. 1c). Studies have shown regulatory crosstalk between iron and zinc as iron

120 starvation was previously shown to increase expression of Zur-regulated genes cntO, cntM, and

121 amiA, but not znuA (50). However, amending sputum samples with excess ferrous iron (1 mM)

122 did not reduce expression of Zur-regulated genes (Fig. 1c). Together these data support the

123 model that $P$. aeruginosa has limited access to zinc in sputum and that zinc and iron limitation are

124 separate signals.

Activation of the Zur-regulated PA3600 promoter in CF sputum is inversely correlated with concentration of zinc in sputum samples

While promoter activity of $P$. aeruginosa grown in CF sputum samples was overall higher

129 than medium controls, there was a range of promoter activity across sputum samples from

130 different subjects (Fig. 1b). We hypothesized that differences in promoter activities between

131 sputum samples from different CF patients were due to differences in sputum zinc concentrations.

132 To test this, inductively coupled plasma mass spectrometry (ICP-MS) was performed on

133 homogenized CF sputum samples to measure total metals (i.e., zinc, iron, and manganese) 
134 concentrations. The ability of these same sputum samples to activate the PA3600 promoter in

135 reporter strain $\mathrm{PAO} 1$ att::P $\mathrm{PA3600}_{\mathrm{A}}$ lacZ was tested in parallel. The data showed a significant inverse

136 correlation between sputum zinc concentration and induction of the PA3600 promoter across

137 tested sputum samples (Fig. 2). There was no significant correlation between sputum iron or

138 manganese concentrations and induction of the PA3600 promoter (Fig. 2b; Fig. S1a; Fig. S1b).

139 Induction of the PA3600 promoter was also compared to clinical information, primarily lung

140 function (FEV1\%) at the time of sputum collection, but there was no correlation found between

141 FEV1\% and PA3600 promoter activity (Fig. S1c). Therefore, the derepression of Zur-regulated

142 genes in $P$. aeruginosa grown in CF sputum inversely correlates with the total zinc concentration

143 in sputum samples.

Recombinant CP induces a $P$. aeruginosa zinc-starvation response in vitro and in expectorated CF sputum sputum sample in our study that elicited the strongest zinc-starvation response had a zinc concentration of $\sim 2 \mu \mathrm{g} / \mathrm{g}(\sim 2000 \mu \mathrm{g} / \mathrm{L}, \sim 31 \mu \mathrm{M})$ (Fig. 2a). Given the concomitant high zinc concentration in our CF sputum samples and the elevated zinc starvation response in $P$. 151 aeruginosa grown in these CF sputum samples, it is likely that the zinc in our CF sputum samples 152 is bound by zinc-sequestering proteins. CP is one such host zinc-sequestering protein that is 153 found in high concentrations in the sputum of CF patients $(2,22)$. CP has also been shown to 154 induce expression of Zur-regulated genes in $P$. aeruginosa strain PA14 (51). Therefore, we 155 hypothesized that CP binds zinc to induce a zinc starvation response in $P$. aeruginosa grown in

156 CF sputum. To test this, we first expressed and purified recombinant human CP as previously 157 described (52) and as illustrated in Fig. S2. The ability of our recombinant CP to induce a zinc158 starvation response was tested by growing $P$. aeruginosa strain PAO1 att:: $\mathrm{P}_{P A 3600}-l a c Z$ in culture 159 medium (LB), medium containing $\mathrm{CP}$, or medium containing $\mathrm{CP}$ and zinc (Fig. 3a). CP 
concentrations in the lung can reach $1 \mathrm{mg} / \mathrm{ml}(\sim 40 \mu \mathrm{M})(29)$, therefore, $1 \mathrm{mg} / \mathrm{ml} \mathrm{CP}$ was used for

161 all CP-based experiments. Growing $P$. aeruginosa in medium containing $1 \mathrm{mg} / \mathrm{ml} \mathrm{CP}$ resulted in

162 a four-fold increase in promoter activation ( 92 MU) compared to the control ( 25 MU) (Fig. 3a).

163 The addition of excess zinc $(1 \mathrm{mM})$ in the presence of CP prevented promoter activation (Fig.

164 3a). These results confirm that our purified recombinant human CP can induce a zinc-starvation

165 response in $P$. aeruginosa which is quenched with the addition of exogenous zinc.

Despite the reportedly high concentrations of CP in the serum, sputum, and BALF of CF

167 patients $(2,21-24), P$. aeruginosa appears to be able to access enough zinc to persist. Various

168 environmental factors may influence CP zinc binding such as calcium concentrations (53), $\mathrm{pH}$

169 (54), or the presence of oxidants $(55,56)$. Additionally, while CP in its tetrameric state is resistant

170 to proteolytic degradation, CP is susceptible to oxidation which in turn makes it susceptible to

171 proteolytic degradation by both host and bacterial proteases $(55,56)$. Because it was unclear if

$172 \mathrm{CP}$ in sputum would remain intact and/or active to bind zinc, we tested the ability of recombinant

173 human $\mathrm{CP}$ to bind zinc and thereby induce a zinc-starvation response in $P$. aeruginosa grown in

174 CF sputum. P. aeruginosa strain PAO1 att::P $\mathrm{PA3600}_{-l a c Z}$ was grown in unamended CF sputum,

175 sputum supplemented with $1 \mathrm{mM}$ zinc, and sputum supplemented with both $1 \mathrm{mM}$ zinc and 1

$176 \mathrm{mg} / \mathrm{ml}(\sim 40 \mu \mathrm{M}) \mathrm{CP}$ (Fig. 3b). The addition of zinc lowered PA3600 promoter activity in sputum

177 (Fig. 3b), supporting our NanoString data (Fig. 1c), while addition of CP to zinc-amended sputum

178 significantly prevented reduction of promoter activity (Fig. 3b). These data confirm that

179 recombinant CP added to CF sputum remains intact to bind zinc, which induces a zinc starvation

180 response in colonizing $P$. aeruginosa.

181 While recombinant CP added to zinc-amended sputum increased $P$. aeruginosa PA3600

182 promoter activity on average compared to zinc-amended sputum controls, the CF sputum

183 samples tested varied in their responses (Fig. 3b, Fig. 1b). The inverse correlation between

184 sputum zinc concentrations and induction of the PA3600 promoter suggests that sputum samples

185 that result in high promoter activity have lower concentrations of zinc than samples that induce 
186 low promoter activity, comparatively (Fig. 2). The high promoter activity by $P$. aeruginosa was

187 readily quenched by the addition of zinc but remained high when CP was also added (Fig. 3b;

188 green, lavender, lilac). Conversely, the low promoter activity by $P$. aeruginosa grown in sputum

189 samples with presumably high zinc is not affected greatly by the addition of zinc nor CP (Fig. 3b;

190 pink, light pink, gray). Overall, these data show that addition of recombinant CP to zinc-amended

191 sputum can induce a zinc-starvation response dependent on sputum zinc concentration.

Zinc metalloproteases are enriched amongst $\boldsymbol{P}$. aeruginosa-secreted zinc-binding proteins

Since both TPEN and CP were confirmed to bind zinc and induce a zinc-starvation

response in $P$. aeruginosa in culture medium (Fig. 1a, Fig. 3a), we wanted to further measure the effects of TPEN- and CP-mediated zinc sequestration on P. aeruginosa growth. Addition of TPEN or $\mathrm{CP}$ to cultures grown in LB decreased the final $\mathrm{OD}_{600}$ of $P$. aeruginosa compared to control aeruginosa grows in the presence of CP under the conditions tested. mediated zinc starvation affects $P$. aeruginosa physiology. Unlike the chemical chelator TPEN,

202 CP is not membrane permeable and instead exerts its effects on pathogens by binding metals in 203 the extracellular environment. CF sputum has been reported to contain high concentrations of 204 both $\mathrm{CP}(2,22,23)$ and secreted $P$. aeruginosa proteases including zinc metalloproteases (57). 205 We performed a UniProt Knowledgebase (UniProtKB) analysis of the $P$. aeruginosa strain PAO1 206 proteome, which identified at least 72 zinc-binding proteins (Table 2). Of those 72, 64 were 207 described by Gene Ontology (GO) molecular function as having catalytic activity (Table 2), which 208 is consistent with the role of zinc as a cofactor. Of those 64 zinc-binding enzymes, 12 were further 209 described as proteases and 5 of those were secreted zinc metalloproteases LasB, LasA, AprA, 210 ImpA, and PepB (Table 2). We performed a second UniProtKB analysis of the $P$. aeruginosa 211 strain PAO1 proteome that identified at least 34 secreted proteins, of which 6 were proteases and 
212 included the 5 aforementioned zinc metalloproteases in addition to Protease IV (PA4175).

213 UniProtKB does not show Protease IV as binding zinc, but Protease IV has been described as a

214 zinc metalloprotease and its enzymatic activity is reduced in a $P$. aeruginosa mutant lacking the

215 zinc importer-encoding gene znuA (14). These analyses suggest that $83-100 \%$ of secreted

216 proteases, important virulence factors, are zinc metalloproteases. Overall, previously published

217 studies and curated databases suggest that $\mathrm{CP}$ and $P$. aeruginosa-secreted zinc

218 metalloproteases are abundant in the extracellular milieu of the CF mucus environment.

Zinc chelation inhibits LasB-mediated proteolysis

221 Given the importance of zinc to the activity of zinc metalloenzymes, we hypothesized that

222 zinc chelation by TPEN and CP would inhibit the activity of secreted zinc metalloproteases. Our

223 initial studies suggested that LasB and LasA accounted for the majority of proteolytic activity by

$224 P$. aeruginosa strain PAO1 (WT) because filtered supernatants from $\triangle$ las $A B$ cultures spotted onto

225 milk plates cleared the milk plates substantially less than filtered WT supernatants (Fig. 4a, inset

226 i-ii). As a result, this study focuses on the effect of zinc chelation on LasB and LasA activity.

227 To test the above hypothesis, LasB activity was determined quantitatively using azocasein

228 as a substrate. The azocasein degradation assay was previously described to measure total

229 proteolytic activity (14). However, by comparing the ability of $P$. aeruginosa WT, $\Delta / a s A$, and

$230 \triangle$ las $A B$ supernatants to degrade azocasein, we found that azocasein degradation was LasB-

231 dependent under the conditions tested (Fig. 4a). As a result, we tested the effect of TPEN and

232 CP on LasB activity using the azocasein degradation assay. $P$. aeruginosa supernatants were

233 filtered and then left untreated, treated with TPEN or CP, or treated with both TPEN or CP and

234 zinc. Treatment with TPEN or CP inhibited LasB enzymatic activity while addition of excess zinc

$235(1 \mathrm{mM})$ in the presence of TPEN or CP restored LasB activity (Fig. 4b, Fig. 4c). Furthermore,

236 treatment of $\triangle$ lasAB supernatants with TPEN (Fig. S3a) or CP (Fig. S3b) without or with the

237 addition of excess zinc did not alter azocasein degradation. Therefore, treatment of $P$. aeruginosa 
cell-free supernatants with zinc chelators TPEN and CP inhibits LasB-mediated caseinolytic activity.

\section{Zinc chelation inhibits LasA-mediated lysis of $S$. aureus}

LasA activity was determined by monitoring the decrease in absorbance at $595 \mathrm{~nm}$ of a

243 heat-killed $S$. aureus suspension as previously described (14). Use of $P$. aeruginosa strain PAO1

244 (WT), $\Delta / a s A$, and $\Delta$ las $A+l a s A$ (complemented mutant) supernatants confirmed that LasA is 245 necessary for the lysis of $S$. aureus and that this assay measures LasA-mediated lysis of $S$. 246 aureus under the conditions tested (Fig. 5a-b). This assay was then used to measure LasA 247 activity in $P$. aeruginosa cell-free supernatants left untreated, treated with TPEN or CP, or treated 248 with both TPEN or CP and zinc. Treatment of supernatants with TPEN or CP inhibited LasA 249 activity while treatment with TPEN or CP in the presence of excess zinc (500 $\mu \mathrm{M}$ and $160 \mu \mathrm{M}$,

250 respectively) restored LasA activity (Fig. 5c-f). Furthermore, treatment of $\Delta$ las $A$ supernatants with

251 zinc, TPEN, or CP had no effect on lysis of S. aureus, confirming that treatment of supernatants

252 did not have LasA-independent cytotoxic effects on S. aureus (Fig. S5). Therefore, treatment of 253 P. aeruginosa cell-free supernatants with zinc chelators TPEN and CP inhibits LasA-mediated 254 lysis of $S$. aureus.

\section{Discussion}

Here we show that $P$. aeruginosa strain PAO1 grown in aliquots of expectorated CF

258 sputum exhibits a zinc-starvation response despite relatively high concentrations of zinc in the 259 sputum samples. Treatment with recombinant host CP was sufficient to induce a zinc-starvation

260 response in $P$. aeruginosa grown in zinc-amended CF sputum samples from different subjects, 261 demonstrating that CP retains its function in sputum. Furthermore, treatment of $P$. aeruginosa 262 supernatants with CP inhibited the activity of secreted, extracellular zinc metalloproteases LasB 263 and LasA. The data presented in this study support a model in which CP released from recruited 
neutrophils sequesters zinc from the environment to induce a zinc-starvation response in $P$. aeruginosa and sequesters zinc from secreted virulence factors including zinc-dependent metalloproteases LasA and LasB inhibiting S. aureus lysis, degradation of peptides, and/or 267 nutrient acquisition (Fig. 6).

A variety of strategies have been used to learn about the environment that $P$. aeruginosa encounters in the CF lung including analysis of bacteria grown in buffered media supplemented

270 with CF sputum compared to bacteria grown in laboratory media $(8,9)$, and direct analysis of 271 gene expression by bacteria in expectorated CF sputum $(4,5,58)$. While studies have varied in 272 their techniques, transcriptomic analyses have found that genes induced by low intracellular zinc 273 are elevated in sputum samples relative to controls (4-9). Our model differs from previous models

274 as it measures the transcriptional response of $P$. aeruginosa grown directly in expectorated 275 sputum from a variety of CF patients. Our study also found that $P$. aeruginosa activates its zinc276 starvation response in CF sputum on average but revealed differences across samples from

277 different CF donors (Fig. 1b-c, Fig. 3b). These findings taken together underscore the fact that

$278 P$. aeruginosa growth in laboratory media would not recapitulate the effect of low-zinc conditions

279 in the context of CF. To this end, our CF sputum model is one way to provide a low-zinc 280 environment and allows for investigation of the response of $P$. aeruginosa across sputum samples 281 from different donors which vary in levels of host factors like CP. This same approach would also 282 enable the investigation of different $P$. aeruginosa strains in sputum aliquots from a single donor. $\mathrm{CP}$ concentrations during infections can reach $1 \mathrm{mg} / \mathrm{ml}$ or $\sim 40 \mu \mathrm{M}$ which is often posited

284 to be higher than or in excess of the bioavailable zinc concentration in most environments (29).

285 However, zinc concentrations in CF sputum are high relative to sputum from non-CF individuals 286 and other biological compartments. Smith et al. (1) found that the zinc concentration of 45 CF 287 sputum samples ranged from $678 \mu \mathrm{g} / \mathrm{L}(\sim 10 \mu \mathrm{M})$ to $1181 \mu \mathrm{g} / \mathrm{L}(\sim 18 \mu \mathrm{M})$ compared to $103 \mu \mathrm{g} / \mathrm{L}$ $288(\sim 2 \mu \mathrm{M})$ to $597 \mu \mathrm{g} / \mathrm{L}(\sim 9 \mu \mathrm{M})$ in 8 non-CF sputum samples. Li et al. (3) reported that the zinc 289 concentration of $118 \mathrm{CF}$ sputum samples ranged from $\sim 5 \mu \mathrm{M}$ to $\sim 145 \mu \mathrm{M}$. In this study, the zinc 
concentration of 8 CF sputum samples ranged from $1.002 \mu \mathrm{g} / \mathrm{g}(\sim 15 \mu \mathrm{M})$ to $7.562 \mu \mathrm{g} / \mathrm{g}(\sim 116 \mu \mathrm{M})$

(Fig. 2a). Therefore, under certain conditions or in some microenvironments, CP may not be in excess of environmental zinc.

There is mounting evidence that divalent-metal sequestration by CP affects $P$. aeruginosa.

Wakeman et al. (51) demonstrated that CP-mediated genetic responses in $P$. aeruginosa were reversed upon treatment with zinc in vitro and that $P$. aeruginosa and $\mathrm{CP}$ colocalized at sites of 296 inflammation within a CF lung explant. D'Orazio et al. showed that CP-mediated growth inhibition 297 was enhanced in $P$. aeruginosa strain $\Delta z n u A$, which is a mutant lacking the gene encoding the 298 small zinc-binding protein of the ZnuABC zinc importer resulting in reduced intracellular zinc accumulation (13, 14). Zygiel et al. (59) showed that treatment with CP significantly reduced intracellular iron and manganese in $P$. aeruginosa, but did not significantly affect intracellular zinc,

301 though intracellular zinc trended downward (59). Our data show that CP induces a Zur-regulated

302 zinc-starvation response in vitro and in expectorated CF sputum which is repressed upon the

303 addition of excess zinc (Fig. 3a-b). We also observed CP-mediated growth defects in vitro (Fig.

304 3c) similar to those reported by Zygiel et al. (59) which were previously attributed to ferrous iron 305 chelation by CP. Taken together, the data show that $P$. aeruginosa and CP colocalize at sites of 306 inflammation in the CF lung and that CP is capable of inducing zinc- and/or iron-starvation 307 responses depending on test conditions.

Additionally, while Filkins et al. (60) showed that in vitro co-culture of $P$. aeruginosa and S. aureus on CF bronchial epithelial cells reduced the viability of $S$. aureus, Wakeman et al. (51)

310 showed that zinc chelation by CP promotes $P$. aeruginosa and $S$. aureus co-culture in in vitro, in 311 vivo, and ex vivo models, in part, by downregulating genes encoding anti-staphylococcal factors 312 such as pyocyanin, hydrogen cyanide, and PQS/HQNO. Interestingly, treatment of $P$. aeruginosa 313 with CP did not reduce the expression of lasA though the functionality of LasA was not tested 314 (51). In this study, we show that CP-mediated zinc chelation inhibits LasA-mediated lysis of S. 315 aureus by $P$. aeruginosa in vitro (Fig. 5e-f). Therefore, while LasA may be expressed and 
secreted by $P$. aeruginosa in the presence of $\mathrm{CP}, \mathrm{CP}$ may post-translationally inhibit LasA activity

317 via zinc sequestration. Furthermore, colonization of the CF airways is usually described as a

318 pattern of succession where $S$. aureus is the predominant colonizer early on in younger patients

319 before being outcompeted by $P$. aeruginosa in older patients (60). However, Fischer et al. (61)

320 recently showed that $P$. aeruginosa and $S$. aureus chronically co-colonize the CF lung. Wakeman

321 et al. also showed that $P$. aeruginosa, $S$. aureus, and CP colocalize in CF lung explants (51).

322 Further studies are required to determine if CP modulates protease-dependent and/or protease-

323 independent co-colonization of $P$. aeruginosa and $S$. aureus in the CF lung.

Notably, $P$. aeruginosa strains chronically adapted to the CF lung, including las $R$ loss-of-

325 function (LasR-) mutants, have a reduced capacity to outcompete $S$. aureus (62). LasR is a QS

326 regulator that positively regulates the expression and secretion of several virulence factors

327 including zinc metalloproteases LasB, LasA, AprA, ImpA, PepB, and Protease IV (34, 35).

328 However, LasR- strains commonly arise during chronic CF infection and are associated with

329 worse lung function (63-68). While LasR- strains are common in CF infections, virulence factors

330 regulated by LasR such as zinc metalloproteases are still reported to be abundant in CF sputum

331 (57). Recent work by Mould et al. showed that when LasR+ and LasR- strains were cocultured,

332 the LasR+ strain increased production of RhIR-controlled virulence factors by the LasR-strain

333 (69). Interestingly, LasB and LasA are reportedly regulated by both the LasR and RhIR QS

334 regulators (35). Therefore, further investigation is needed to understand how intra- and

335 interspecies interactions within populations colonizing the CF airway impact the secretion and

336 function of virulence factors such as zinc metalloproteases LasB and LasA.

337 LasB is an abundant protease with broad substrate specificity that is implicated in amino

338 acid liberation and consumption (70). In addition to nutrient acquisition, LasB also plays a role in

339 the ability of $P$. aeruginosa to invade host epithelial cells (39) and to evade host immune

340 responses via processes such as degrading cytokines (40). Interestingly, degradation of pro-

341 inflammatory cytokines IL-8 and IL-6 by LasB reduces neutrophil recruitment and the overall IL-8 
342 and IL-6 response (40). While LasB-mediated cytokine degradation has been reported to reduce

343 neutrophil recruitment, LasB can also induce neutrophil extracellular traps (NETs) $(71,72)$.

344 Neutrophils recruited to sites of inflammation can release CP through processes such as NET

345 formation (73) and in this study we show that CP-mediated zinc chelation inhibits the activity of

346 secreted LasB (Fig. 4c). Taken together, there appears to be a complex interplay between LasB,

347 neutrophils, and CP during the course of infection which may contribute to exacerbations in CF.

348 Furthermore, recent work suggests that secreted LasB activates Protease IV which then

349 predominantly processes and activates LasA $(36,37)$. Therefore, CP-mediated inhibition of

350 secreted LasB activity may have downstream effects on the processing and activity of other

351 secreted zinc metalloproteases.

352 In conclusion, the results of our study show that CP can induce a zinc-starvation response

353 in $P$. aeruginosa in CF sputum as well as chelate zinc to inhibit the activity of virulence-associated

354 zinc metalloproteases. Future studies will focus on how competition for zinc in a zinc-limited or

355 zinc-chelating environment such as CF mucus shapes polymicrobial infections and patient

356 outcomes, particularly considering the observed variability in zinc concentration and availability

357 across CF patients. 


\section{Materials and Methods}

\section{Strains and growth conditions}

360 Bacterial strains and plasmids used in this study are listed in Table S1. $P$. aeruginosa and

361 Escherichia coli strains were maintained on lysogeny broth (LB) (1\% tryptone, $0.5 \%$ yeast extract,

$3620.5 \% \mathrm{NaCl}$ ) with $1.5 \%$ agar and routinely grown in LB on a roller drum at $37^{\circ} \mathrm{C}$ LB. $P$. aeruginosa

363 plasmid strains were maintained by supplementing media with $300 \mu \mathrm{g} / \mathrm{ml}$ carbenicillin or $60 \mu \mathrm{g} / \mathrm{ml}$

364 gentamicin. E. coli plasmid strains were maintained by supplementing media with $100 \mu \mathrm{g} / \mathrm{ml}$

365 carbenicillin. S. aureus SH1000 was maintained on trypticase soy with $1.5 \%$ agar (TSA) or grown

366 in trypticase soy broth (TSB) on a roller drum at $37^{\circ} \mathrm{C}$. Saccharomyces cerevisiae strains for 367 cloning were maintained on yeast-peptone-dextrose (YPD) medium with 2\% agar.

\section{Construction of plasmids}

370 Primers used for plasmid construction are listed in Table S2. All plasmids were sequenced at the

371 Molecular Biology Core at the Geisel School of Medicine at Dartmouth. Plasmid GH121_P PA3600-

372 lacZ (DH3229) was constructed using a S. cerevisiae recombination technique as previously

373 described (74). Plasmid GH121_P $P_{p q s A}-l a c Z$ served as the vector backbone for this construct.

374 GH121_P $P_{P A 3600}-l a c Z$ was purified from yeast using Zymoprep ${ }^{\mathrm{TM}}$ Yeast Plasmid Miniprep II

375 according to manufacturer's protocol and transformed into electrocompetent $E$. coli strain S17 by

376 electroporation. The plasmid was introduced into $P$. aeruginosa by conjugation and recombinants

377 were obtained using sucrose counter-selection and genotype screening by PCR.

379 Complementation plasmid pMQ70_lasA was generated using the NEBuilder HiFi DNA assembly 380 cloning kit (New England BioLabs). P. aeruginosa strain PAO1V $\Delta$ lasA was complemented in

381 trans by inserting a functional copy of lasA amplified from PAO1V genomic DNA into plasmid 382 pMQ70 under the control of the arabinose-inducible $B A D$ promoter generating plasmid 383 pMQ70_lasA. Plasmid pMQ70_lasA was transformed into $\Delta / a s A$ by electroporation. 


\section{Cystic Fibrosis (CF) sputum collection}

386 Sputum samples were collected in accordance with protocols approved by the Committee for the

387 Protection of Human Subjects at Dartmouth. Expectorated sputum samples used in this study 388 were collected from adult subjects with CF during a routine office visit or upon admission for 389 treatment of a disease exacerbation. Sputum samples were frozen upon collection and stored at $390-80^{\circ} \mathrm{C}$ until use.

\section{Beta-galactosidase ( $\beta$-Gal) assay}

$393 P$. aeruginosa cells with a promoter fusion to lacZ integrated at the att locus were grown in $5 \mathrm{~mL}$ cultures of $\mathrm{LB}$ at $37^{\circ} \mathrm{C}$ for $16 \mathrm{~h}$. Overnight cultures were diluted $1: 50 \mathrm{in} 50 \mathrm{ml}$ culture medium (LB or $\mathrm{M63}$ ) and then grown to an $\mathrm{OD}_{600}$ of 0.5 . The cells were then centrifuged at $4,500 \times \mathrm{g}$ for 10 min, resuspended in culture medium, centrifuged at $10,000 \times \mathrm{g}$ for $2 \mathrm{~min}$, and then resuspended in $500 \mu \mathrm{l}$ culture medium. Ten $\mu \mathrm{l}$ of cell suspension were added per $100 \mu \mathrm{l}$ culture medium or sputum sample in a $2 \mathrm{ml}$ microcentrifuge tube. Samples were incubated at $37^{\circ} \mathrm{C}$ with shaking for $3 \mathrm{~h}$. $\beta$-Gal activity was measured as described by Miller (75) using $50 \mu \mathrm{l}$ of sample.

400

\section{RNA isolation and NanoString analysis}

402 Unamended sputum or sputum amended with $1 \mathrm{mM} \mathrm{ZnSO} 4 \cdot 7 \mathrm{H}_{2} \mathrm{O}$ or $\left(\mathrm{NH}_{4}\right)_{2} \mathrm{Fe}\left(\mathrm{SO}_{4}\right)_{2} \cdot 6 \mathrm{H}_{2} \mathrm{O}$ $403(100 \mu \mathrm{L})$ was added to $2 \mathrm{ml}$ microcentrifuge tubes. $P$. aeruginosa strain PAO1 was grown in $5 \mathrm{~mL}$ 404 cultures of LB at $37^{\circ} \mathrm{C}$ for $16 \mathrm{~h}$. Overnight cultures were diluted 1:50 in $50 \mathrm{ml} \mathrm{M} 63$ minimal medium 405 with $0.2 \%$ glucose and then grown to an $\mathrm{OD}_{600}$ of 0.5 . The cells were then centrifuged at $4,500 \mathrm{x}$ $406 \mathrm{~g}$ for $10 \mathrm{~min}$, washed with water, centrifuged, and then resuspended in $500 \mu \mathrm{l}$ water. Ten $\mu \mathrm{l}$ of cell 407 suspension were added per $100 \mu \mathrm{l} \mathrm{M63} \mathrm{minimal} \mathrm{medium} \mathrm{with} 0.2 \%$ glucose (control) or sputum 408 sample in a $2 \mathrm{ml}$ microcentrifuge tube. Samples were then incubated at $37^{\circ} \mathrm{C}$ with shaking for 3 409 h. TriZol $(900 \mu \mathrm{l})$ was added to $100 \mu \mathrm{l}$ sputum containing $10 \mu \mathrm{l}$ of PAO1 cell suspension. Samples 
410 were stored overnight. RNA was prepared following DirectZol kit instructions and eluted in $50 \mu \mathrm{l}$

411 water.

412

413 For NanoString, $5 \mu$ l of a 1:10 dilution of RNA was used. Diluted RNA was applied to the codeset

414 PaV4 and processed as previously reported (49). Counts were normalized to the geometric mean

415 of spiked-in technical controls. Normalized counts were used for Z-score calculations and 416 heatmap construction.

\section{Measurement of zinc in sputum samples}

419 Sputum samples for zinc analysis were stored at $-80^{\circ} \mathrm{C}$ until processed. Sputum zinc was 420 quantified by inductively coupled plasma-mass spectrometry (ICP-MS) following nitric acid 421 digestion of organic material according to the method of Heck et al. and is expressed as $\mu g$ zinc 422 per g of sputum (76). ICP-MS was performed by the Dartmouth Trace Element Analysis (TEA) 423 Core.

\section{Expression and Purification of recombinant calprotectin (CP)}

426 Plasmid S100A8/A9 was obtained from Futami et al. (52) and recombinant CP was expressed

427 and purified as previously described with minor modification. Plasmid S100A8/A9 was first 428 confirmed by Sanger sequencing and then transformed into E. coli T7 Express cells. Transformed 429 T7 Express cells were then grown in LB containing $100 \mu \mathrm{g} / \mathrm{ml}$ carbenicillin at $37^{\circ} \mathrm{C}$ with shaking 430 and induced at about an $\mathrm{OD}_{600}$ of 0.5 with $0.5 \mathrm{mM} \beta$-D-1-thiogalactopyranoside (IPTG) for $3 \mathrm{~h}$.

431 Cultures were centrifuged at $13,260 \times \mathrm{g}$ for $10 \mathrm{~min}$ at $4^{\circ} \mathrm{C}$. Supernatant was discarded. Cell pellets 432 were resuspended in $30 \mathrm{ml}$ wash solution (150 mM NaCl), transferred to a $50 \mathrm{ml}$ conical tube, 433 and then centrifuged at $3,210 \times \mathrm{g}$ for $10 \mathrm{~min}$ at $4^{\circ} \mathrm{C}$. Supernatant was discarded. Pellets were 434 weighed and then stored at $-20^{\circ} \mathrm{C}$. 
436 Cell pellets were resuspended in $85 \mathrm{~mL}$ lysis buffer $(50 \mathrm{mM}$ Tris- $\mathrm{HCl} \mathrm{pH}$ 7.5, $50 \mathrm{mM} \mathrm{NaCl}, 5 \mathrm{mM}$

$437 \mathrm{MgCl}_{2}$ ) supplemented with Benzonase-HC to control viscosity of the sample. Cells were then

438 lysed using the microfluidizer with 3 passages at 18,000 psi. Final volume was about $100 \mathrm{ml} .15 \%$

439 polyethylenimine (PEI) was added dropwise to a final concentration of $0.7 \%$ to precipitate nucleic

440 acids (about $5 \mathrm{ml}$ ). Samples were then centrifuged at $23,280 \times \mathrm{g}$ for $10 \mathrm{~min}$ at $4^{\circ} \mathrm{C}$. Pellet

441 containing intact cells and precipitated nucleic acids was discarded. $\mathrm{NH}_{4} \mathrm{SO}_{4}(61.27 \mathrm{~g})$ was added

442 slowly to clarified supernatant (about $115 \mathrm{ml}$ ) while stirring at $4^{\circ} \mathrm{C}$ until a saturation of $80 \%$. The

443 sample become gradually turbid. Sample was stirred for an additional 30 min after complete

444 saturation. Sample was then centrifuged at $23,280 \times \mathrm{g}$ for $10 \mathrm{~min}$ at $4^{\circ} \mathrm{C}$. Supernatant was

445 discarded and the pellet was dissolved in about $30 \mathrm{ml}$ solubilization buffer $(50 \mathrm{mM}$ Tris- $\mathrm{HCl} \mathrm{pH}$

$4467.5,30 \mathrm{mM}$ dithiothreitol [DTT]) and incubated for $1 \mathrm{~h}$ at $37^{\circ} \mathrm{C}$. Dissolved pellet was transferred to

447 dialysis cassettes and dialyzed overnight in $50 \mathrm{mM}$ sodium phosphate $\mathrm{pH} 6.0$ at $4^{\circ} \mathrm{C}$ using 3.5

448 kDa cut-off dialysis cassettes to change buffer. Sample was then centrifuged at 23,280 $\mathrm{g}$ for 10

$449 \min$ at $4^{\circ} \mathrm{C}$ to remove any pellet.

451 CP was then purified using a HiTrap SP column (stored in $20 \%$ ethanol). The column was washed

452 with 5 column volumes $(\mathrm{CV})$ of $\mathrm{H}_{2} \mathrm{O}$ at about $5 \mathrm{ml} / \mathrm{min}$. The column was then washed with $5 \mathrm{CV}$

453 of $100 \%$ SP Sepharose HP buffer B (50 mM sodium phosphate pH 6.0, $1 \mathrm{mM} \mathrm{DTT,} 1 \mathrm{M} \mathrm{NaCl}$;

454 filtered/degassed) at about $5 \mathrm{ml} / \mathrm{min}$. The column was equilibrated with $10 \mathrm{CV}$ of SP Sepharose

455 HP buffer A (50 mM sodium phosphate $\mathrm{pH}$ 6.0, $1 \mathrm{mM} \mathrm{DTT}$; filtered/degassed) at about $5 \mathrm{ml} / \mathrm{min}$.

456 A superloop was assembled with the appropriate volume for sample application. Sample was then

457 loaded in the column using the superloop at $2.5 \mathrm{ml} / \mathrm{min}$. The column was then washed with 10

458 CV of SP Sepharose HP buffer A at about $5 \mathrm{ml} / \mathrm{min}$. The column was then washed with a step

459 gradient of SP Sepharose HP buffer B: 5 CV of 5\% SP Sepharose HP buffer B, 10 CV at $30 \%$ SP

460 Sepharose HP buffer B and 5 CV at $100 \%$ SP Sepharose HP buffer B at about $5 \mathrm{ml} / \mathrm{min}$. 
461 Fractions were analyzed using SDS-PAGE (15\% gel) and the appropriate fractions were then

462 pooled.

463

464 CP was then purified using a HiLoad 26/600 Sephadex S75 and CP buffer (50 mM Tris- $\mathrm{HCl} \mathrm{pH}$

$4657.5,150 \mathrm{mM} \mathrm{NaCl}, 1 \mathrm{mM}$ DTT; filtered/degassed). Sample (about $13 \mathrm{ml}$ ) was loaded in a $50 \mathrm{ml}$

466 superloop. Sample was then run on the HiLoad 26/600 Superdex 75p, a program composed of 2

467 CV equilibration, injection of $12 \mathrm{ml}$ sample and elution with $1.2 \mathrm{CV}$ at $2.6 \mathrm{ml} / \mathrm{min}$. Flow rate is 2.6

$468 \mathrm{ml} / \mathrm{min}$ and collection of $7 \mathrm{ml} /$ tube. Tubes corresponding to three different fractions were pooled

469 to make fractions F1_I, F2_I, and F3_I. All other tubes containing calprotectin from both HiTrap

470 runs were concentrated using YM-10 Amicon centrifugal filters and re-loaded in the HiLoad

$47126 / 600$ superdex 75 as before. Tubes corresponding to three different fractions were pooled to

472 make fractions F1_II, F2_II, and F3_II. Samples from all six fractions were analyzed using SDS-

473 PAGE (4-12\% gel). Fractions F1_I and F1_II, F2_I and F2_II, and F3_I and F3_II were combined

474 to make fractions F1, F2, and F3, respectively. Fractions were concentrated with YM-10 Amicon

475 centrifugal filters. The final concentrations of the fractions were determined using a Bradford

476 protein assay.

477

478 Protease assays

$479 P$. aeruginosa culture supernatants were used for protease assays. $5 \mathrm{ml}$ overnight cultures in LB

480 were centrifuged at $4,500 \times \mathrm{g}$ for $10 \mathrm{~min}$. Supernatants were then filter sterilized using a $0.22 \mu \mathrm{m}$

481 syringe filter. For TPEN experiments, undiluted supernatants were used. For CP experiments,

482 stored aliquots of CP were first diluted to $3 \mathrm{mg} / \mathrm{ml}$ in $\mathrm{CP}$ buffer without DTT (50 mM Tris- $\mathrm{HCl} \mathrm{pH}$

$4837.5,150 \mathrm{mM} \mathrm{NaCl})$. Then 1 part $3 \mathrm{mg} / \mathrm{ml} \mathrm{CP}$ was added to 2 parts supernatant for a final

484 concentration of $1 \mathrm{mg} / \mathrm{ml}$.

485 
Caseinolytic activity was determined qualitatively by spotting $P$. aeruginosa supernatants onto $1 \%$

487 milk plates or quantitatively using azocasein as a substrate as previously described (14) with

488 modification. In brief, $P$. aeruginosa culture supernatants were treated overnight (16 h) with 50

$489 \mu \mathrm{M}$ TPEN or an equivalent volume of $100 \% \mathrm{EtOH}, 1 \mathrm{mg} / \mathrm{ml}(\sim 40 \mu \mathrm{M}) \mathrm{CP}$ or an equivalent volume

490 of CP buffer without DTT, and/or $1 \mathrm{mM} \mathrm{ZnSO}_{4} \cdot 7 \mathrm{H}_{2} \mathrm{O}$ or an equivalent volume of $\mathrm{diH}_{2} \mathrm{O}$.

491 Treatment of WT supernatants with $50 \mu \mathrm{M}$ to $2 \mathrm{mM} \mathrm{ZnSO}_{4} \cdot 7 \mathrm{H}_{2} \mathrm{O}$ was found not to affect LasB

492 activity (Fig. S3c). The supernatants were then incubated at $37^{\circ} \mathrm{C}$ overnight (16 h). Supernatants

493 (25 $\mu \mathrm{l})$ were mixed with $150 \mu \mathrm{l} 2 \%$ azocasein in $10 \mathrm{mM}$ Tris- $\mathrm{HCl}, 8 \mathrm{mM} \mathrm{CaCl}$, $\mathrm{pH}$ 7.4. Samples

494 were incubated at $37^{\circ} \mathrm{C}$ for $15 \mathrm{~min} .228 \mu \mathrm{l}$ of $10 \%$ TCA were added to each sample, vortexed,

495 then incubated at room temperature for $15 \mathrm{~min}$. Samples were then centrifuged for $10 \mathrm{~min}$ at

$49610,000 \times \mathrm{g}$. Cleared supernatants $(100 \mu \mathrm{l})$ were added to wells of a 96 -well flat-bottom polystyrene

497 plate containing $200 \mu \mathrm{l} 1 \mathrm{M} \mathrm{NaOH}$. Absorbance was read at $440 \mathrm{~nm}$.

Staphylolytic activity was determined by monitoring the decrease in absorbance at $595 \mathrm{~nm}$ of a killed by heating at $100^{\circ} \mathrm{C}$ for $30 \mathrm{~min}$. Heat-killed S. aureus suspensions were cooled to room

504 temperature before use. $P$. aeruginosa culture supernatants were treated overnight (16 h) with 50 $505 \mu \mathrm{M}$ TPEN or an equivalent volume of $100 \% \mathrm{EtOH}, 1 \mathrm{mg} / \mathrm{ml}(\sim 40 \mu \mathrm{M}) \mathrm{CP}$ or an equivalent volume 506 of CP buffer without DTT, and/or 160-500 $\mu \mathrm{MnSO}_{4} \cdot 7 \mathrm{H}_{2} \mathrm{O}$ or an equivalent volume of diH $\mathrm{Zn}_{2} \mathrm{O}$

507 Because increasing concentrations of zinc were previously reported to inhibit LasA activity (46),

508 an appropriate concentration of zinc to use in add-back experiments was determined 509 experimentally. For undiluted WT supernatants, the addition of $500 \mu \mathrm{M}$ zinc had no effect on LasA 510 activity, while increasing concentrations of zinc inhibited LasA-mediated lysis of S. aureus (Fig. 511 S4a-b). Therefore, we used $500 \mu \mathrm{M}$ zinc for TPEN-based experiments. For CP-buffer diluted WT 
512 supernatants, the addition of $50 \mu \mathrm{M}$ zinc had no effect on LasA activity, while increasing

513 concentrations of zinc inhibited LasA-mediated lysis of S. aureus (Fig. S4c-d). However, a

514 tetramer of CP can potentially bind up to four zinc ions. Therefore, to ensure that zinc would be

515 in excess in CP-based experiments, we used $160 \mu \mathrm{M}$ zinc which was four times the concentration

516 of $\mathrm{CP}$ but still less than $250 \mu \mathrm{M}$ zinc which was the concentration tested that started to inhibit

517 LasA activity independent of CP. P. aeruginosa supernatants $(20 \mu \mathrm{l})$ were added to $180 \mu \mathrm{l}$ of heat-

518 killed $S$. aureus in wells of a 96-well flat-bottom polystyrene plate. Staphylolytic activity was

519 determined by monitoring the change in absorbance at $595 \mathrm{~nm}$ every $15 \mathrm{~min}$ for $3 \mathrm{~h}$ using a plate

520 reader. The plate was shaken before each read.

521

522 Statistical analysis

523 Statistical analysis was performed using GraphPad Prism 8 and results were expressed as the

524 mean values plus or minus standard deviations. Unless otherwise noted, one-way analysis of

525 variance (ANOVA) followed by Tukey's multiple-comparison test was performed to determine

526 statistical significance of the data. See the figure legends for other specific statistical tests used.

\section{Acknowledgements}

529 We would like to thank Pat Occhipinti for generating the promoter-lacZ fusion reporter strain used

530 in this study, Andreia Verissimo of the Institute for Biomolecular Targeting (bioMT) Molecular

531 Tools Core (MTC) for her assistance in expressing and purifying recombinant calprotectin used

532 in this study, and Nick Jacobs and Georgia Doing for their insightful comments and feedback

533 during manuscript preparation. Research reported in this publication was supported by the Cystic

534 Fibrosis Foundation (CFF) grants GIFFOR1610 and GIFFOR17Y5 awarded to A.H.G. and CFF

535 grant HOGAN19G0 awarded to D.A.H. Support for the project was also provided by bioMT

536 through NIH NIGMS grant P20 GM113132, the Dartmouth Cystic Fibrosis Research Center

537 (DartCF) through NIH NIDDK grant P30 DK117469, the CFF Research Development Program 
bioRxiv preprint doi: https://doi.org/10.1101/2021.02 25.432981; this version posted March 1, 2021. The copyright holder for this preprint (which was not certified by peer review) is the author/funder, who has granted bioRxiv a license to display the preprint in perpetuity. It is made available under aCC-BY-NC 4.0 International license.

538 (CF RDP) through CFF grant STANTO19R0, and the Dartmouth Trace Element Analysis (TEA)

539 Core through NIH NIEHS P42 ES007373. The content of this publication is solely the

540 responsibility of the authors and does not necessarily represent the official views of the funding

541 sources. 


\section{References}

543 1. Smith DJ, Anderson GJ, Bell SC, Reid DW. 2014. Elevated metal concentrations in the 544 CF airway correlate with cellular injury and disease severity. J Cyst Fibros 13:289-95.

545 2. Gray RD, Duncan A, Noble D, Imrie M, O'Reilly DS, Innes JA, Porteous DJ, Greening AP, 546 Boyd AC. 2010. Sputum trace metals are biomarkers of inflammatory and suppurative $547 \quad$ lung disease. Chest 137:635-41.

548 3. Li K, Gifford AH, Hampton TH, O'Toole GA. 2020. Availability of zinc impacts interactions 549 between Streptococcus sanguinis and Pseudomonas aeruginosa in coculture. J Bacteriol 550202.

551 4. Cornforth DM, Dees JL, Ibberson CB, Huse HK, Mathiesen IH, Kirketerp-Moller K, Wolcott 552 RD, Rumbaugh KP, Bjarnsholt T, Whiteley M. 2018. Pseudomonas aeruginosa 553 transcriptome during human infection. Proc Natl Acad Sci U S A 115:E5125-E5134.

554 5. Cornforth DM, Diggle FL, Melvin JA, Bomberger JM, Whiteley M. 2020. Quantitative 555 framework for model evaluation in microbiology research using Pseudomonas aeruginosa

557 6. Mastropasqua MC, Lamont I, Martin LW, Reid DW, D'Orazio M, Battistoni A. 2018. 558 Efficient zinc uptake is critical for the ability of Pseudomonas aeruginosa to express 559 virulence traits and colonize the human lung. J Trace Elem Med Biol 48:74-80.

560 7. Tan J, Doing G, Lewis KA, Price CE, Chen KM, Cady KC, Perchuk B, Laub MT, Hogan 561 DA, Greene CS. 2017. Unsupervised extraction of stable expression signatures from 562 public compendia with an ensemble of neural networks. Cell Syst 5:63-71.e6.

563 8. Palmer KL, Mashburn LM, Singh PK, Whiteley M. 2005. Cystic fibrosis sputum supports 564 growth and cues key aspects of Pseudomonas aeruginosa physiology. J Bacteriol $565 \quad 187: 5267-77$. 
566 9. Turner KH, Wessel AK, Palmer GC, Murray JL, Whiteley M. 2015. Essential genome of 567 Pseudomonas aeruginosa in cystic fibrosis sputum. Proc Natl Acad Sci U S A 112:4110$568 \quad 5$.

569 10. Ellison ML, Farrow JM, Parrish W, Danell AS, Pesci EC. 2013. The transcriptional regulator Np20 is the zinc uptake regulator in Pseudomonas aeruginosa. PLoS One

572 11. Mikhaylina A, Ksibe AZ, Scanlan DJ, Blindauer CA. 2018. Bacterial zinc uptake regulator $573 \quad$ proteins and their regulons. Biochem Soc Trans 46:983-1001.

574 12. Novichkov PS, Brettin TS, Novichkova ES, Dehal PS, Arkin AP, Dubchak I, Rodionov DA. 2012. RegPrecise web services interface: Programmatic access to the transcriptional regulatory interactions in bacteria reconstructed by comparative genomics. Nucleic Acids

578 13. Pederick VG, Eijkelkamp BA, Begg SL, Ween MP, McAllister LJ, Paton JC, McDevitt CA. 2015. ZnuA and zinc homeostasis in Pseudomonas aeruginosa. Sci Rep 5:13139.

580 14. D'Orazio M, Mastropasqua MC, Cerasi M, Pacello F, Consalvo A, Chirullo B, Mortensen B, Skaar EP, Ciavardelli D, Pasquali P, Battistoni A. 2015. The capability of Pseudomonas aeruginosa to recruit zinc under conditions of limited metal availability is affected by inactivation of the ZnuABC transporter. Metallomics 7:1023-35.

584 15. Mastropasqua MC, D'Orazio M, Cerasi M, Pacello F, Gismondi A, Canini A, Canuti L, S, Richaud P, Bleves S, Ball G, Borezée-Durant E, Lobinski R, Pignol D, Arnoux P, Voulhoux R. 2017. Pseudomonas aeruginosa zinc uptake in chelating environment is primarily mediated by the metallophore pseudopaline. Sci Rep 7:17132. 
592 17. Makarova KS, Ponomarev VA, Koonin EV. 2001. Two C or not two C: Recurrent disruption of Zn-ribbons, gene duplication, lineage-specific gene loss, and horizontal gene transfer in evolution of bacterial ribosomal proteins. Genome Biol 2:RESEARCH 0033.

595 18. Blaby-Haas CE, Furman R, Rodionov DA, Artsimovitch I, de Crecy-Lagard V. 2011. Role of a $\mathrm{Zn}$-independent DksA in $\mathrm{Zn}$ homeostasis and stringent response. Mol Microbiol 79:700-15.

19. Gabriel SE, Helmann JD. 2009. Contributions of Zur-controlled ribosomal proteins to

20. Hood MI, Skaar EP. 2012. Nutritional immunity: Transition metals at the pathogen-host interface. Nat Rev Microbiol 10:525-37.

602 21. Barthe C, Figarella C, Carrere J, Guy-Crotte O. 1991. Identification of 'cystic fibrosis protein' as a complex of two calcium-binding proteins present in human cells of myeloid origin. Biochim Biophys Acta 1096:175-7.

22. Gray RD, MacGregor G, Noble D, Imrie M, Dewar M, Boyd AC, Innes JA, Porteous DJ, Greening AP. 2008. Sputum proteomics in inflammatory and suppurative respiratory diseases. Am J Respir Crit Care Med 178:444-52.

23. Gray RD, Imrie M, Boyd AC, Porteous D, Innes JA, Greening AP. 2010. Sputum and serum calprotectin are useful biomarkers during CF exacerbation. J Cyst Fibros 9:193-8.

24. MacGregor G, Gray RD, Hilliard TN, Imrie M, Boyd AC, Alton EW, Bush A, Davies JC,

613 25. Edgeworth J, Gorman M, Bennett R, Freemont P, Hogg N. 1991. Identification of p8,14 as a highly abundant heterodimeric calcium binding protein complex of myeloid cells. $\mathrm{J}$

616 26. Gebhardt C, Németh J, Angel P, Hess J. 2006. S100A8 and S100A9 in inflammation and cancer. Biochem Pharmacol 72:1622-31. 
618 27. Strupat K, Rogniaux H, Van Dorsselaer A, Roth J, Vogl T. 2000. Calcium-induced noncovalently linked tetramers of MRP8 and MRP14 are confirmed by electrospray ionization-mass analysis. J Am Soc Mass Spectrom 11:780-8.

621 28. Korndörfer IP, Brueckner F, Skerra A. 2007. The crystal structure of the human $(\mathrm{S} 100 \mathrm{~A} 8 / \mathrm{S} 100 \mathrm{~A} 9)_{2}$ heterotetramer, calprotectin, illustrates how conformational changes of interacting alpha-helices can determine specific association of two EF-hand proteins. J

625 29. Zygiel EM, Nolan EM. 2018. Transition metal sequestration by the host-defense protein calprotectin. Annu Rev Biochem 87:621-643.

627 30. Liu JZ, Jellbauer S, Poe AJ, Ton V, Pesciaroli M, Kehl-Fie TE, Restrepo NA, Hosking MP, Edwards RA, Battistoni A, Pasquali P, Lane TE, Chazin WJ, Vogl T, Roth J, Skaar EP, Raffatellu M. 2012. Zinc sequestration by the neutrophil protein calprotectin enhances Salmonella growth in the inflamed gut. Cell Host Microbe 11:227-39.

631 31. Grim KP, San Francisco B, Radin JN, Brazel EB, Kelliher JL, Parraga Solorzano PK, Kim PC, McDevitt CA, Kehl-Fie TE. 2017. The Metallophore staphylopine enables Staphylococcus aureus to compete with the host for zinc and overcome nutritional

635 32. Hood MI, Mortensen BL, Moore JL, Zhang Y, Kehl-Fie TE, Sugitani N, Chazin WJ, Caprioli RM, Skaar EP. 2012. Identification of an Acinetobacter baumannii zinc acquisition system

639 33. Isaksen B, Fagerhol MK. 2001. Calprotectin inhibits matrix metalloproteinases by

641 34. Schuster M, Lostroh CP, Ogi T, Greenberg EP. 2003. Identification, timing, and signal specificity of Pseudomonas aeruginosa quorum-controlled genes: A transcriptome analysis. J Bacteriol 185:2066-79. 
644 35. Nouwens AS, Beatson SA, Whitchurch CB, Walsh BJ, Schweizer HP, Mattick JS, Cordwell SJ. 2003. Proteome analysis of extracellular proteins regulated by the las and $r h /$ quorum sensing systems in Pseudomonas aeruginosa PAO1. Microbiology (Reading) 149:1311-

36. Li $\mathrm{XH}$, Lee JH. 2019. Quorum sensing-dependent post-secretional activation of

37. Oh J, Li XH, Kim SK, Lee JH. 2017. Post-secretional activation of Protease IV by quorum sensing in Pseudomonas aeruginosa. Sci Rep 7:4416.

652 38. Bruce MC, Poncz L, Klinger JD, Stern RC, Tomashefski JF, Dearborn DG. 1985. Biochemical and pathologic evidence for proteolytic destruction of lung connective tissue

39. Cowell BA, Twining SS, Hobden JA, Kwong MSF, Fleiszig SMJ. 2003. Mutation of lasA and lasB reduces Pseudomonas aeruginosa invasion of epithelial cells. Microbiology

40. LaFayette SL, Houle D, Beaudoin T, Wojewodka G, Radzioch D, Hoffman LR, Burns JL, Dandekar AA, Smalley NE, Chandler JR, Zlosnik JE, Speert DP, Bernier J, Matouk E,

41. Bardoel BW, Hartsink D, Vughs MM, de Haas CJ, van Strijp JA, van Kessel KP. 2012. 2012. Pseudomonas aeruginosa alkaline protease blocks complement activation via the classical and lectin pathways. J Immunol 188:386-93. 
43. Kessler E, Safrin M, Olson JC, Ohman DE. 1993. Secreted LasA of Pseudomonas aeruginosa is a staphylolytic protease. J Biol Chem 268:7503-8.

671 44. Spencer J, Murphy LM, Conners R, Sessions RB, Gamblin SJ. 2010. Crystal structure of

45. Cahan R, Axelrad I, Safrin M, Ohman DE, Kessler E. 2001. A secreted aminopeptidase of Pseudomonas aeruginosa: Identification, primary structure, and relationship to other

46. Kessler E, Safrin M, Abrams WR, Rosenbloom J, Ohman DE. 1997. Inhibitors and specificity of Pseudomonas aeruginosa LasA. J Biol Chem 272:9884-9.

47. Bertuchi FR, Papai R, Ujevic M, Gaubeur I, Cerchiaro G. 2014. General chelating action of copper, zinc and iron in mammalian cells. Analytical Methods 6:8488-8493.

48. Gifford AH, Willger SD, Dolben EL, Moulton LA, Dorman DB, Bean H, Hill JE, Hampton Immun 84:2995-3006.

49. Grahl N, Dolben EL, Filkins LM, Crocker AW, Willger SD, Morrison HG, Sogin ML, Ashare

50. Nelson CE, Huang W, Brewer LK, Nguyen AT, Kane MA, Wilks A, Oglesby-Sherrouse AG. 2019. Proteomic analysis of the Pseudomonas aeruginosa iron starvation response reveals PrrF small regulatory RNA-dependent iron regulation of twitching motility, amino acid metabolism, and zinc homeostasis proteins. J Bacteriol 201.

51. Wakeman CA, Moore JL, Noto MJ, Zhang Y, Singleton MD, Prentice BM, Gilston BA, Doster RS, Gaddy JA, Chazin WJ, Caprioli RM, Skaar EP. 2016. The innate immune 
protein calprotectin promotes Pseudomonas aeruginosa and Staphylococcus aureus interaction. Nat Commun 7:11951.

696 52. Futami J, Atago Y, Azuma A, Putranto EW, Kinoshita R, Murata H, Sakaguchi M. 2016.

53. Stephan JR, Nolan EM. 2016. Calcium-induced tetramerization and zinc chelation shield human calprotectin from degradation by host and bacterial extracellular proteases. Chem

54. Rosen T, Nolan EM. 2020. Metal sequestration and antimicrobial activity of human

55. Hoskin TS, Crowther JM, Cheung J, Epton MJ, Sly PD, Elder PA, Dobson RCJ, Kettle AJ,

Dickerhof N. 2019. Oxidative cross-linking of calprotectin occurs in vivo, altering its structure and susceptibility to proteolysis. Redox Biol 24:101202.

56. Stephan JR, Yu F, Costello RM, Bleier BS, Nolan EM. 2018. Oxidative post-translational modifications accelerate proteolytic degradation of calprotectin. J Am Chem Soc

57. Jaffar-Bandjee MC, Lazdunski A, Bally M, Carrère J, Chazalette JP, Galabert C. 1995. Production of elastase, exotoxin A, and alkaline protease in sputa during pulmonary exacerbation of cystic fibrosis in patients chronically infected by Pseudomonas

58. Rossi E, Falcone M, Molin S, Johansen HK. 2018. High-resolution in situ transcriptomics

59. Zygiel EM, Nelson CE, Brewer LK, Oglesby-Sherrouse AG, Nolan EM. 2019. The human of Pseudomonas aeruginosa unveils genotype independent patho-phenotypes in cystic fibrosis lungs. Nat Commun 9:3459.

innate immune protein calprotectin induces iron starvation responses in Pseudomonas aeruginosa. J Biol Chem 294:3549-3562. 
720 60. Filkins LM, Graber JA, Olson DG, Dolben EL, Lynd LR, Bhuju S, O'Toole GA. 2015. Coculture of Staphylococcus aureus with Pseudomonas aeruginosa drives S. aureus towards fermentative metabolism and reduced viability in a cystic fibrosis model. $\mathrm{J}$ Bacteriol 197:2252-64.

724 61. Fischer AJ, Singh SB, LaMarche MM, Maakestad LJ, Kienenberger ZE, Peña TA, Stoltz DA, Limoli DH. 2020. Sustained coinfections with Staphylococcus aureus and Pseudomonas aeruginosa in cystic fibrosis. Am J Respir Crit Care Med.

727 62. Baldan R, Cigana C, Testa F, Bianconi I, De Simone M, Pellin D, Di Serio C, Bragonzi A, Cirillo DM. 2014. Adaptation of Pseudomonas aeruginosa in cystic fibrosis airways influences virulence of Staphylococcus aureus in vitro and murine models of co-infection. PLoS One 9:e89614.

731 63. Marvig RL, Sommer LM, Molin S, Johansen HK. 2015. Convergent evolution and adaptation of Pseudomonas aeruginosa within patients with cystic fibrosis. Nat Genet 47:57-64.

734 64. Smith EE, Buckley DG, Wu Z, Saenphimmachak C, Hoffman LR, D'Argenio DA, Miller SI, Ramsey BW, Speert DP, Moskowitz SM, Burns JL, Kaul R, Olson MV. 2006. Genetic adaptation by Pseudomonas aeruginosa to the airways of cystic fibrosis patients. Proc Natl Acad Sci U S A 103:8487-92.

738 65. Hansen SK, Rau MH, Johansen HK, Ciofu O, Jelsbak L, Yang L, Folkesson A, Jarmer H, Pseudomonas aeruginosa in the paranasal sinuses of cystic fibrosis children have

742 66. Köhler T, Buckling A, van Delden C. 2009. Cooperation and virulence of clinical 743 Pseudomonas aeruginosa populations. Proc Natl Acad Sci U S A 106:6339-44. 
744 67. Hoffman LR, Kulasekara HD, Emerson J, Houston LS, Burns JL, Ramsey BW, Miller SI. 2009. Pseudomonas aeruginosa las $R$ mutants are associated with cystic fibrosis lung disease progression. J Cyst Fibros 8:66-70.

747 68. Jiricny N, Molin S, Foster K, Diggle SP, Scanlan PD, Ghoul M, Johansen HK, Santorelli Pseudomonas aeruginosa infecting lungs of patients with cystic fibrosis. PLoS One

69. Mould DL, Botelho NJ, Hogan DA. 2020. Intraspecies signaling between common variants of Pseudomonas aeruginosa increases production of quorum-sensing-controlled virulence factors. mBio 11.

754 70. Flynn JM, Phan C, Hunter RC. 2017. Genome-wide survey of Pseudomonas aeruginosa PA14 reveals a role for the glyoxylate pathway and extracellular proteases in the utilization of mucin. Infect Immun 85.

757 71. Skopelja S, Hamilton BJ, Jones JD, Yang ML, Mamula M, Ashare A, Gifford AH, Rigby WF. 2016. The role for neutrophil extracellular traps in cystic fibrosis autoimmunity. JCI Insight 1:e88912.

72. Skopelja-Gardner S, Theprungsirikul J, Lewis KA, Hammond JH, Carlson KM, Hazlett HF,

764 73. Urban CF, Ermert D, Schmid M, Abu-Abed U, Goosmann C, Nacken W, Brinkmann V, Jungblut PR, Zychlinsky A. 2009. Neutrophil extracellular traps contain calprotectin, a cytosolic protein complex involved in host defense against Candida albicans. PLoS Pathog 5:e1000639. 
bioRxiv preprint doi: https://doi.org/10.1101/2021.02 25.432981; this version posted March 1, 2021. The copyright holder for this preprint (which was not certified by peer review) is the author/funder, who has granted bioRxiv a license to display the preprint in perpetuity. It is made available under aCC-BY-NC 4.0 International license.

768 74. Shanks RM, Caiazza NC, Hinsa SM, Toutain CM, O'Toole GA. 2006. Saccharomyces cerevisiae-based molecular tool kit for manipulation of genes from gram-negative bacteria. Appl Environ Microbiol 72:5027-36.

771 75. Miller JH. 1992. A short course in bacterial genetics. Cold Spring Harbor Press.

772 76. Heck JE, Andrew AS, Onega T, Rigas JR, Jackson BP, Karagas MR, Duell EJ. 2009. Lung

773 cancer in a U.S. population with low to moderate arsenic exposure. Environ Health $774 \quad$ Perspect 117:1718-23.

775 77. Horsburgh MJ, Aish JL, White IJ, Shaw L, Lithgow JK, Foster SJ. 2002. SigmaB modulates 776 virulence determinant expression and stress resistance: Characterization of a functional 777 rsbU strain derived from Staphylococcus aureus 8325-4. J Bacteriol 184:5457-67. 


\section{Figure Legends}

780 Fig. 1 P. aeruginosa inoculated into expectorated CF sputum from different donors exhibits a

781 zinc-starvation response. (a) P. aeruginosa strain PAO1 P PA3600-lacZ was grown in LB (Control),

782 LB with $50 \mu \mathrm{M}$ TPEN (TPEN), or LB with $50 \mu \mathrm{M}$ TPEN and $1 \mathrm{mM} \mathrm{ZnSO}{ }_{4} \cdot 7 \mathrm{H}_{2} \mathrm{O}(\mathrm{TPEN}+\mathrm{Zn})$ for

$7833 \mathrm{~h}$. The data shown represent the mean \pm SD from three independent experiments. (b) $P$.

784 aeruginosa strain PAO1 P PA3600-lacZ was grown in M63 (Control), M63 with $50 \mu \mathrm{M}$ TPEN (TPEN),

785 or expectorated CF sputum (sputum) for $3 \mathrm{~h}$. Each point in the sputum set indicates a separate

786 sample from a different donor. The data were analyzed by Brown-Forsythe and Welch ANOVA

787 with Dunnett's T3 multiple comparisons test. (c) P. aeruginosa strain PAO1 was inoculated into

788 M63 (M63) or into sputum from two different donors (Sputum 1 and Sputum 2). The sputum was

789 divided and left untreated (Sputum), treated with $1 \mathrm{mM} \mathrm{ZnSO}_{4} \cdot 7 \mathrm{H}_{2} \mathrm{O}$ (Sputum+Zn), or treated

790 with $1 \mathrm{mM}\left(\mathrm{NH}_{4}\right)_{2} \mathrm{Fe}\left(\mathrm{SO}_{4}\right)_{2} \cdot 6 \mathrm{H}_{2} \mathrm{O}$ (Sputum+Fe). Each condition was analyzed in triplicate. The

791 same lowercase letters indicate samples that are not significantly different and different lowercase

792 letters indicate significant differences $(p<0.05) .{ }^{*} p<0.05,{ }^{* *} p<0.01$

793

794 Fig. 2 Activation of the PA3600 promoter in CF sputum by $P$. aeruginosa is inversely correlated

795 with total sputum zinc concentration. (a) P. aeruginosa strain PAO1 P PA3600-lacZ was inoculated

796 into 8 different CF sputum samples. Zinc concentration of the same 8 CF sputum samples was

797 determined by ICP-MS. B-Gal activity on the left y-axis (Miller Units; gray bars) was then

798 compared to sputum zinc concentration on the right $y$-axis ( $\mu \mathrm{g} / \mathrm{g}$; red dots), (b) Pearson correlation

799 matrix comparing B-Gal activity (Miller units), sputum zinc concentration, sputum iron

800 concentration, and sputum manganese concentration. ${ }^{*} p<0.05,{ }^{* *} p<0.01$

802 Fig. 3 Recombinant human CP added to CF sputum and culture medium induces a zinc-starvation

803 response by $P$. aeruginosa. (a) $P$. aeruginosa strain PAO1 $P_{P A 3600-l a c Z}$ was grown in culture 804 medium (Control), medium with $40 \mu \mathrm{M} \mathrm{CP}(\mathrm{CP})$, or medium with $40 \mu \mathrm{M} \mathrm{CP}$ and $1 \mathrm{mM} \mathrm{ZnSO}{ }_{4} \cdot 7$ 
$805 \mathrm{H}_{2} \mathrm{O}(\mathrm{CP}+\mathrm{Zn})$ for $3 \mathrm{~h}$. The data shown represent the mean $\pm \mathrm{SD}$ from three independent

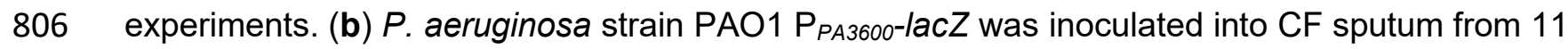

807 different donors. The sputum was divided and left untreated (Control), treated with $100 \mu \mathrm{M} \mathrm{ZnSO} 4$

$808 \cdot 7 \mathrm{H}_{2} \mathrm{O}(\mathrm{Zn})$, or treated with $40 \mu \mathrm{M} \mathrm{CP}$ and $100 \mu \mathrm{M} \mathrm{ZnSO}_{4} \cdot 7 \mathrm{H}_{2} \mathrm{O}(\mathrm{CP}+\mathrm{Zn})$ for $3 \mathrm{~h}$. Different color

809 dots represent samples from different donors. The same color dots connected by a line are from

810 the same CF sputum donor. Data were analyzed by RM one-way ANOVA with Tukey's multiple

811 comparisons test. (c) Representative growth curves of $P$. aeruginosa strain PAO1 PA3600-lacZ

812 grown in LB, LB containing $50 \mu \mathrm{M}$ TPEN, or LB containing $40 \mu \mathrm{M}$ CP. Data shown represent the

813 mean \pm SD of three technical replicates and are representative of three independent experiments.

814 (d) $\mathrm{OD}_{600}$ at $16 \mathrm{~h}$ of $P$. aeruginosa strain PAO1 $\mathrm{P}_{P A 3600}-$ lacZ grown in LB, LB containing $50 \mu \mathrm{M}$

815 TPEN, or LB containing $40 \mu \mathrm{M} \mathrm{CP}$. Data shown represent the mean \pm SD of three independent

816 experiments. The same lowercase letters indicate samples that are not significantly different and

817 different lowercase letters indicate significant differences $(p<0.05)$.

819 Fig. 4 Zinc chelation inhibits LasB enzymatic activity. (a) Filtered supernatants from $16 \mathrm{~h}$ cultures

820 of WT, $\triangle l a s A$, and $\triangle l a s A B$ were incubated with $2 \%$ azocasein for $15 \mathrm{~min}$. Inset are images

821 showing the ability of (i) WT and (ii) $\triangle$ las $A B$ cell-free supernatants to clear milk plates after $16 \mathrm{~h}$.

822 (b) Filtered supernatants from WT $16 \mathrm{~h}$ cultures were left untreated (Control), treated with $50 \mu \mathrm{M}$

823 TPEN (TPEN), or treated with $50 \mu \mathrm{M}$ TPEN and $1 \mathrm{mM} \mathrm{ZnSO}_{4} \bullet 7 \mathrm{H}_{2} \mathrm{O}(\mathrm{TPEN}+\mathrm{Zn}$ ) for an additional

$82416 \mathrm{~h}$. Supernatants were then incubated with $2 \%$ azocasein for $15 \mathrm{~min}$. The data shown represent

825 the mean \pm SD from three independent experiments. (c) Filtered supernatants from WT $16 \mathrm{~h}$ 826 cultures were left untreated (Control), treated with $40 \mu \mathrm{M} \mathrm{CP}(\mathrm{CP})$, or treated with $40 \mu \mathrm{M} \mathrm{CP}$ and

$8271 \mathrm{mM} \mathrm{ZnSO}_{4} \cdot 7 \mathrm{H}_{2} \mathrm{O}(\mathrm{CP}+\mathrm{Zn})$ for an additional $16 \mathrm{~h}$. Supernatants were then incubated with $2 \%$

828 azocasein for $15 \mathrm{~min}$. The same lowercase letters indicate samples that are not significantly

829 different and different lowercase letters indicate significant differences $(p<0.05)$. An enzyme unit

$830(\mathrm{U})$ is defined as $1 \mu \mathrm{mol} \mathrm{min}^{-1}$. 
832 Fig. 5 Zinc chelation inhibits LasA enzymatic activity. (a-b) Lysis of heat-killed S. aureus strain

$833 \mathrm{SH} 1000$ by cell-free supernatants from WT, $\Delta$ las $A$, and $\Delta$ las $A+l a s A$ ( $\Delta$ las $A$ complemented in

834 trans under the Control of arabinose-inducible $\left.\mathrm{P}_{\mathrm{BAD}}\right) 16 \mathrm{~h}$ cultures. (c-d) Lysis of heat-killed S.

835 aureus strain SH1000 by WT and $\Delta / a s A$ cell-free supernatants. WT supernatant was divided and

836 left untreated (WT), treated with $50 \mu \mathrm{M}$ TPEN (WT+TPEN), or treated with $50 \mu \mathrm{M}$ TPEN and 500

$837 \mu \mathrm{M} \mathrm{ZnSO}_{4} \cdot 7 \mathrm{H}_{2} \mathrm{O}(\mathrm{WT}+\mathrm{TPEN}+\mathrm{Zn})$. (e-f) Lysis of heat-killed S. aureus strain SH1000 by WT and

$838 \Delta$ lasA cell-free supernatants. WT supernatant was divided and left untreated (WT), treated with

$83940 \mu \mathrm{M} \mathrm{CP}(\mathrm{WT}+\mathrm{CP})$, or treated with $40 \mu \mathrm{M} \mathrm{CP}$ and $160 \mu \mathrm{M} \mathrm{ZnSO}{ }_{4} \cdot 7 \mathrm{H}_{2} \mathrm{O}(\mathrm{WT}+\mathrm{CP}+\mathrm{Zn}) .(\mathbf{a}),(\mathbf{c})$,

840 (e) The data represent the mean from three independent experiments. Error bars have been

841 omitted for clarity. (b), (d), (f) Quantification of data in (a), (c), and (e), respectively, using area

842 under the curve (AUC). Data are the mean \pm SD from three independent experiments. The same

843 lowercase letters indicate samples that are not significantly different and different lowercase

844 letters indicate significant differences $(p<0.05)$.

846 Fig. 6 Model of the effects of CP-mediated zinc chelation in the CF lung on $P$. aeruginosa. $P$.

847 aeruginosa colonizes the mucus in the airways of CF patients to high densities, which in part

848 requires the uptake and utilization of zinc. At high densities, $P$. aeruginosa secretes a variety of

849 quorum sensing-dependent virulence factors including zinc metalloproteases such as LasB and

850 LasA. LasB is a protease that can degrade host proteins, such as elastin, as well as peptides.

851 These degraded proteins/peptides can then be taken up and utilized as nutrients by $P$.

852 aeruginosa. LasA is a protease that lyses $S$. aureus by cleaving pentaglycine bridges of

853 peptidoglycan. LasA-mediated lysis of $S$. aureus allows $P$. aeruginosa to take up nutrients

854 released from lysed S. aureus as well as to outcompete $S$. aureus in the CF lung. During infection,

855 neutrophils are recruited to sites of infection/inflammation. Neutrophils may then release cellular

856 contents such as CP. CP can then bind bioavailable zinc away from $P$. aeruginosa thus reducing 
bioRxiv preprint doi: https://doi.org/10.1101/2021 02.25 .432981 ; this version posted March 1, 2021. The copyright holder for this preprint (which was not certified by peer review) is the author/funder, who has granted bioRxiv a license to display the preprint in perpetuity. It is made available under aCC-BY-NC 4.0 International license.

857 the overall abundance of $P$. aeruginosa, while also inducing a zinc-starvation response by $P$.

858 aeruginosa. Additionally, CP can bind zinc away from both LasB and LasA thereby inhibiting their

859 proteolytic activity. Furthermore, LasB and LasA activity have been shown to induce neutrophil

860 extracellular traps (NETs). Therefore, CP-mediated inhibition of LasB and LasA activity may lead

861 to less NET formation and, subsequently, less CP release. Black arrows indicate a positive

862 interaction. Red arrows indicate an inhibitory interaction. 
864 Table 1 Zinc metalloproteases secreted by $P$. aeruginosa

\begin{tabular}{lll}
\hline Gene Number $^{a}$ & PDB Entry $^{b}$ & Protein Name and Description \\
\hline PA0572 & 5KDW & $\begin{array}{l}\text { ImpA, immunomodulating metalloprotease of } \\
\text { P. aeruginosa }\end{array}$ \\
PA1249 & 1KAP & AprA, alkaline metalloprotease or aeruginolysin \\
PA1871 & 3IT5 & LasA, staphylolytic protease \\
PA2939 & N/A & PepB or PaAP, aminopeptidase \\
PA3724 & 1EZM & LasB, elastase or pseudolysin \\
PA4175 & N/A & Protease IV, endoprotease
\end{tabular}

865 a From P. aeruginosa genome website, https://www.pseudomonas.com/.

$866{ }^{b}$ From Protein Data Bank (PDB) website, https://www.rcsb.org/.

868 Table 2 Characteristics of zinc-binding proteins in P. aeruginosa as annotated by UniProtKB ${ }^{a}$

\begin{tabular}{|c|c|c|c|c|c|}
\hline \multirow[b]{2}{*}{ GO Molecular Function ${ }^{b}$} & \multirow[b]{2}{*}{$\begin{array}{l}\text { Number of } \\
\text { Proteins }\end{array}$} & \multicolumn{4}{|c|}{ Subcellular Localization } \\
\hline & & Secreted & $\begin{array}{c}\text { Inner } \\
\text { Membrane }\end{array}$ & Cytoplasm & Not Listed \\
\hline Zinc-Binding & 72 & 8 & 5 & 21 & 38 \\
\hline $\begin{array}{l}\text { Catalytic Activity: } \\
\text { Non-peptidase }\end{array}$ & 52 & 3 & - & 16 & 33 \\
\hline $\begin{array}{l}\text { Catalytic Activity: } \\
\text { Peptidase }\end{array}$ & 12 & 5 & 3 & 1 & 3 \\
\hline Structural Binding Activity & 2 & - & - & - & 2 \\
\hline $\begin{array}{l}\text { Molecular } \quad \text { Function } \\
\text { Regulator }\end{array}$ & 2 & - & - & 1 & 1 \\
\hline $\begin{array}{l}\text { ATPase-Coupled Protein } \\
\text { Transmembrane } \\
\text { Transporter Activity }\end{array}$ & 1 & - & 1 & - & - \\
\hline
\end{tabular}


a

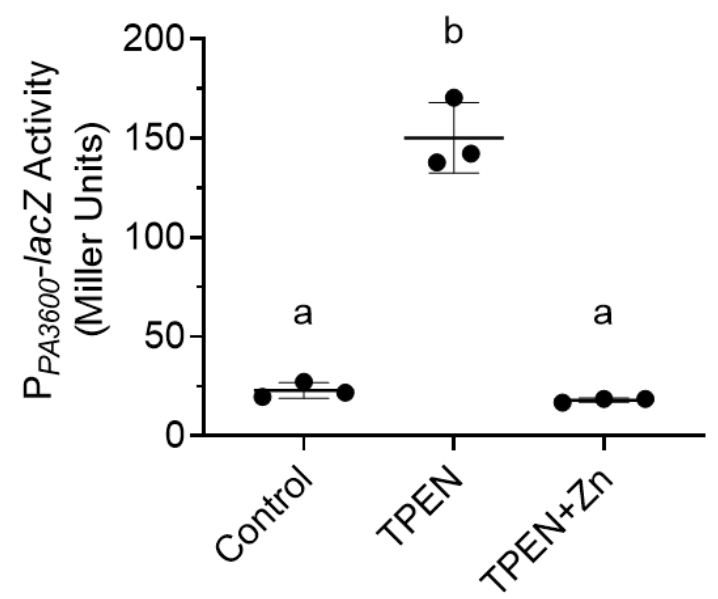

b

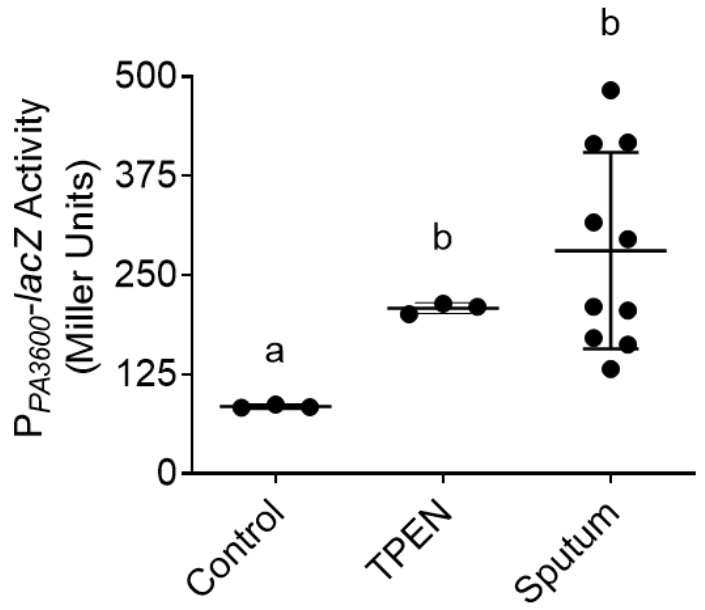

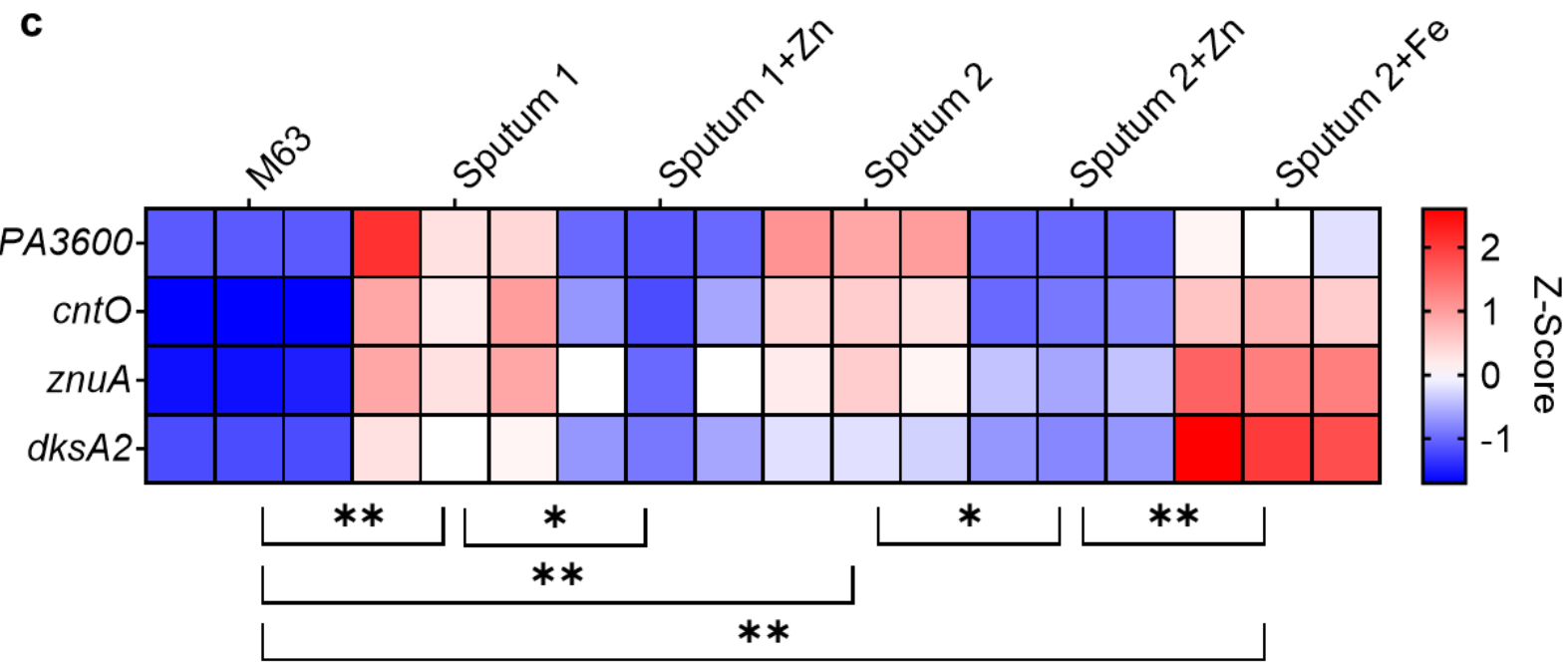

Fig. $1 P$. aeruginosa inoculated into expectorated CF sputum from different donors exhibits a zinc-starvation response. (a) $P$. aeruginosa strain PAO1 $\mathrm{P}_{P A 3600}$-lacZ was grown in LB (Control), LB with $50 \mu \mathrm{M}$ TPEN (TPEN), or LB with $50 \mu \mathrm{M} \mathrm{TPEN}$ and $1 \mathrm{mM} \mathrm{ZnSO}_{4} \cdot 7 \mathrm{H}_{2} \mathrm{O}$ (TPEN+Zn) for $3 \mathrm{~h}$. The data shown represent the mean \pm SD from three independent experiments. (b) $P$. aeruginosa strain PAO1 $\mathrm{P}_{P A 3600}-$ lacZ was grown in M63 (Control), M63 with $50 \mu \mathrm{M}$ TPEN (TPEN), or expectorated CF sputum (sputum) for $3 \mathrm{~h}$. Each point in the sputum set indicates a separate sample from a different donor. The data were analyzed by Brown-Forsythe and Welch ANOVA with Dunnett's T3 multiple comparisons test. (c) $P$. aeruginosa strain PAO1 was inoculated into M63 (M63) or into sputum from two different donors (Sputum 1 and Sputum 2). The sputum was divided and left untreated (Sputum), treated with $1 \mathrm{mM} \mathrm{ZnSO}_{4} \cdot 7 \mathrm{H}_{2} \mathrm{O}($ Sputum+Zn), or treated with $1 \mathrm{mM}\left(\mathrm{NH}_{4}\right)_{2} \mathrm{Fe}\left(\mathrm{SO}_{4}\right)_{2} \cdot 6 \mathrm{H}_{2} \mathrm{O}(\mathrm{Sputum}+\mathrm{Fe})$. Each condition was analyzed in triplicate. The same lowercase letters indicate samples that are not significantly different and different lowercase letters indicate significant differences $(p<0.05) .{ }^{*} p<0.05,{ }^{* *} p<0.01$ 
a

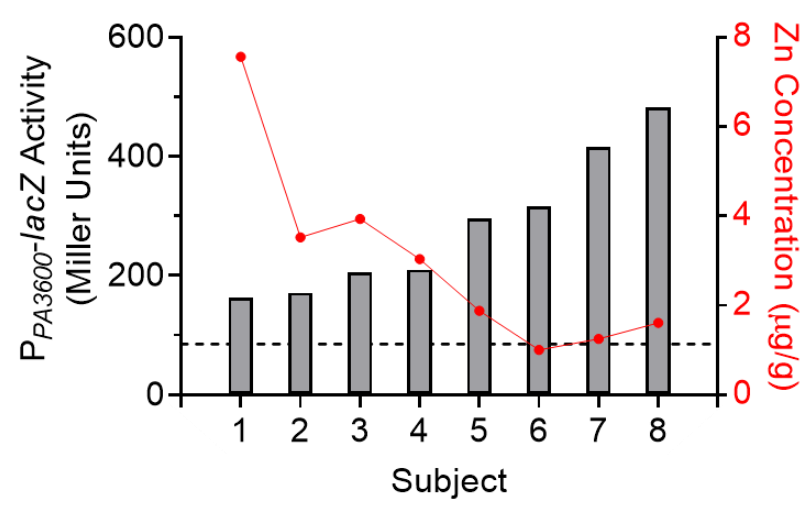

b

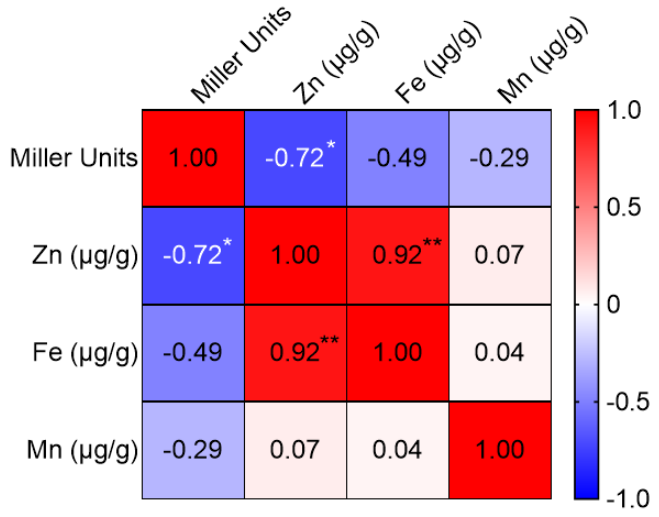

Fig. 2 Activation of the PA3600 promoter in CF sputum by $P$. aeruginosa is inversely correlated with total sputum zinc concentration. (a) $P$. aeruginosa strain PAO1 $\mathrm{P}_{P A 3600}$-lacZ was inoculated into 8 different CF sputum samples. Zinc concentration of the same 8 CF sputum samples was determined by ICP-MS. B-Gal activity on the left y-axis (Miller Units; gray bars) was then compared to sputum zinc concentration on the right y-axis ( $\mu \mathrm{g} / \mathrm{g}$; red dots), (b) Pearson correlation matrix comparing B-Gal activity (Miller units), sputum zinc concentration, sputum iron concentration, and sputum manganese concentration. ${ }^{*} p<0.05,{ }^{* *} p<0.01$ 
a

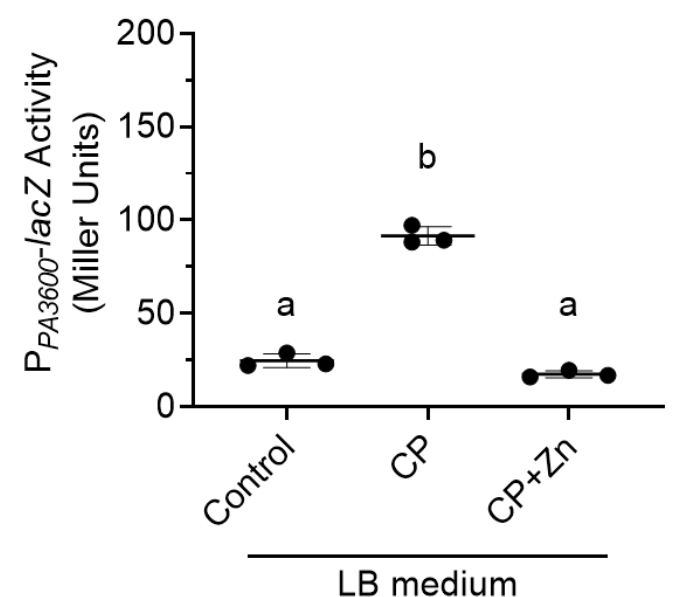

C

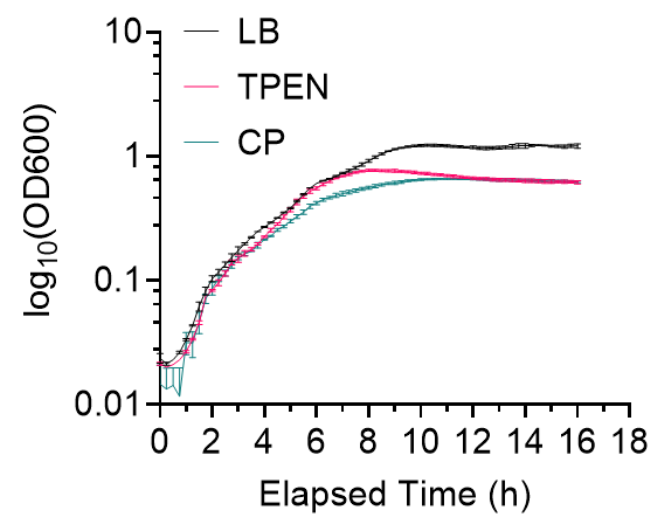

b

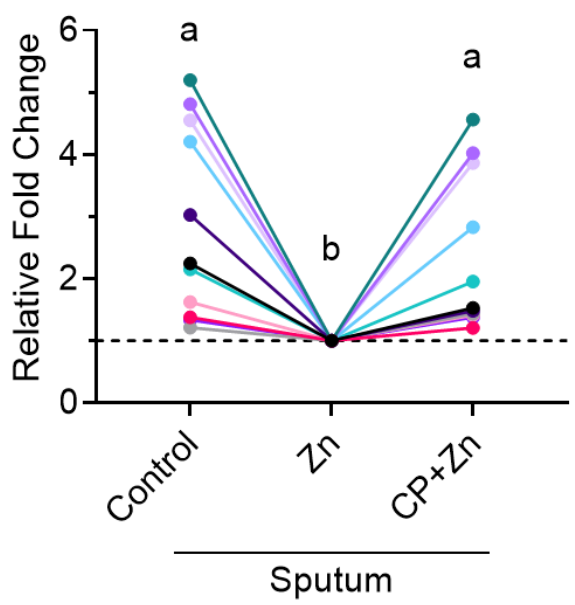

d

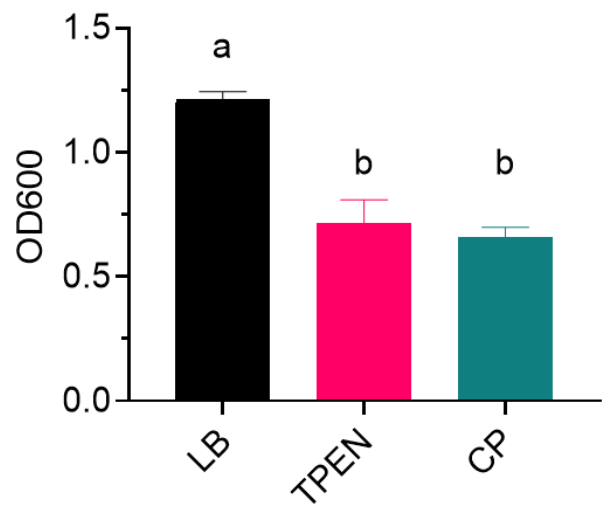

Fig. 3 Recombinant human CP added to CF sputum and culture medium induces a zinc-starvation response by $P$. aeruginosa. (a) $P$. aeruginosa strain $P A O 1 \mathrm{P}_{P A 3600}-$ lacZ was grown in culture medium (Control), medium with $40 \mu \mathrm{M} \mathrm{CP}(\mathrm{CP})$, or medium with $40 \mu \mathrm{M} \mathrm{CP}$ and $1 \mathrm{mM} \mathrm{ZnSO}_{4} \cdot 7$ $\mathrm{H}_{2} \mathrm{O}(\mathrm{CP}+\mathrm{Zn})$ for $3 \mathrm{~h}$. The data shown represent the mean $\pm \mathrm{SD}$ from three independent experiments. (b) $P$. aeruginosa strain PAO1 $\mathrm{P}_{P A 3600}$-lacZ was inoculated into CF sputum from 11 different donors. The sputum was divided and left untreated (Control), treated with $100 \mu \mathrm{M} \mathrm{ZnSO}_{4}$ - $7 \mathrm{H}_{2} \mathrm{O}(\mathrm{Zn})$, or treated with $40 \mu \mathrm{M} \mathrm{CP}$ and $100 \mu \mathrm{M} \mathrm{ZnSO}_{4} \cdot 7 \mathrm{H}_{2} \mathrm{O}(\mathrm{CP}+\mathrm{Zn})$ for $3 \mathrm{~h}$. Different color dots represent samples from different donors. The same color dots connected by a line are from the same CF sputum donor. Data were analyzed by RM one-way ANOVA with Tukey's multiple comparisons test. (c) Representative growth curves of $P$. aeruginosa strain PAO1 $\mathrm{P}_{P A 3600}-l a c Z$ grown in LB, LB containing $50 \mu \mathrm{M}$ TPEN, or LB containing $40 \mu \mathrm{M}$ CP. Data shown represent the mean $\pm S D$ of three technical replicates and are representative of three independent experiments. (d) $\mathrm{OD}_{600}$ at $16 \mathrm{~h}$ of $P$. aeruginosa strain PAO1 $\mathrm{P}_{P A 3600}$-lacZ grown in LB, LB containing $50 \mu \mathrm{M}$ TPEN, or LB containing $40 \mu \mathrm{M} \mathrm{CP}$. Data shown represent the mean \pm SD of three independent experiments. The same lowercase letters indicate samples that are not significantly different and different lowercase letters indicate significant differences $(p<0.05)$. 
a

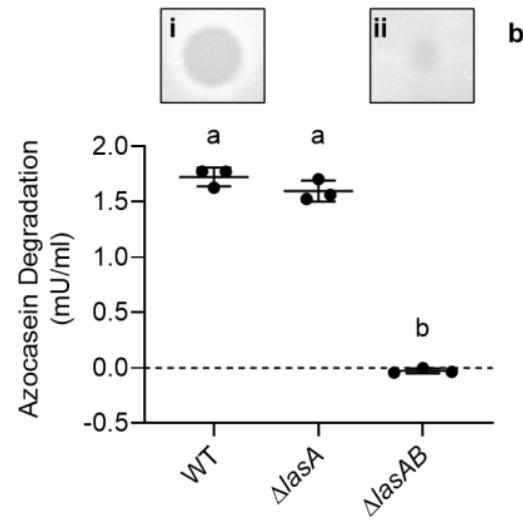

\section{b}
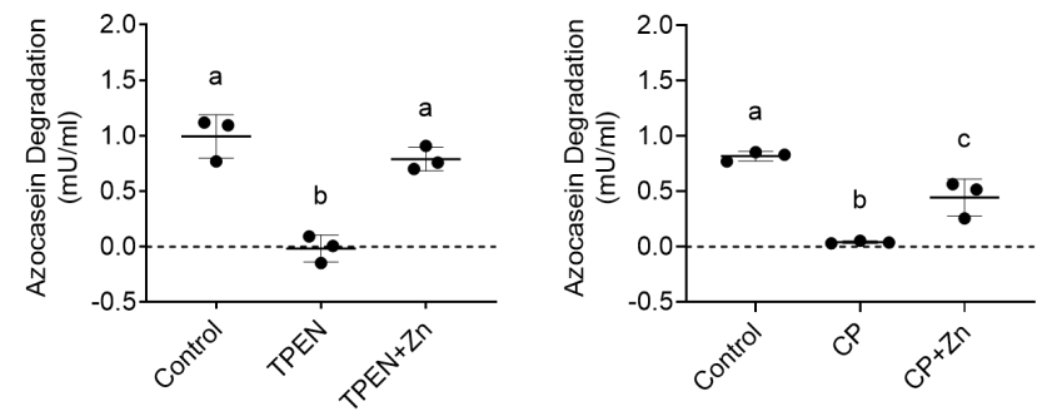

Fig. 4 Zinc chelation inhibits LasB enzymatic activity. (a) Filtered supernatants from $16 \mathrm{~h}$ cultures of WT, $\triangle$ las $A$, and $\triangle$ las $A B$ were incubated with $2 \%$ azocasein for 15 min. Inset are images showing the ability of (i) WT and (ii) $\triangle$ las $A B$ cell-free supernatants to clear milk plates after $16 \mathrm{~h}$. (b) Filtered supernatants from WT $16 \mathrm{~h}$ cultures were left untreated (Control), treated with $50 \mu \mathrm{M}$ TPEN (TPEN), or treated with $50 \mu \mathrm{M}$ TPEN and $1 \mathrm{mM} \mathrm{ZnSO}_{4} \cdot 7 \mathrm{H}_{2} \mathrm{O}(\mathrm{TPEN}+\mathrm{Zn}$ ) for an additional $16 \mathrm{~h}$. Supernatants were then incubated with $2 \%$ azocasein for $15 \mathrm{~min}$. The data shown represent the mean \pm SD from three independent experiments. (c) Filtered supernatants from WT $16 \mathrm{~h}$ cultures were left untreated (Control), treated with $40 \mu \mathrm{M} \mathrm{CP}(\mathrm{CP})$, or treated with $40 \mu \mathrm{M} \mathrm{CP}$ and $1 \mathrm{mM} \mathrm{ZnSO}_{4} \cdot 7 \mathrm{H}_{2} \mathrm{O}(\mathrm{CP}+\mathrm{Zn})$ for an additional $16 \mathrm{~h}$. Supernatants were then incubated with $2 \%$ azocasein for $15 \mathrm{~min}$. The same lowercase letters indicate samples that are not significantly different and different lowercase letters indicate significant differences $(p<0.05)$. An enzyme unit $(U)$ is defined as $1 \mu \mathrm{mol} \mathrm{min}{ }^{-1}$. 
a

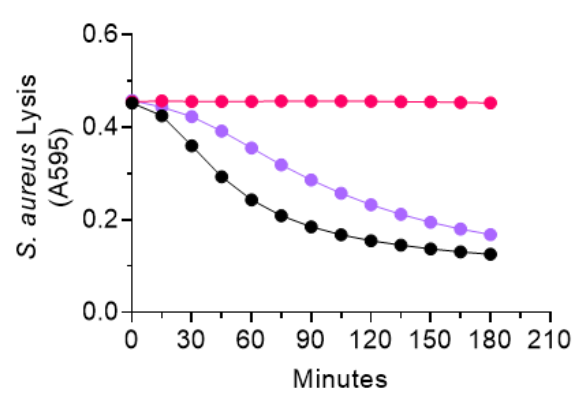

C

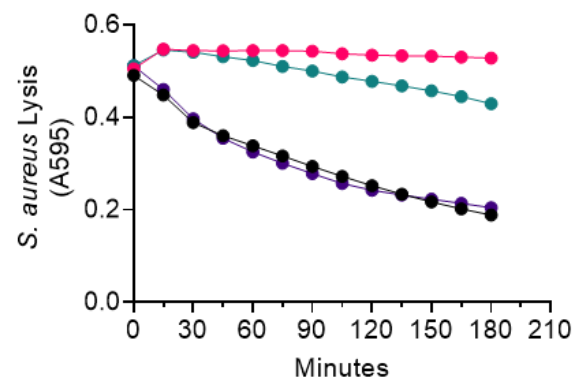

e

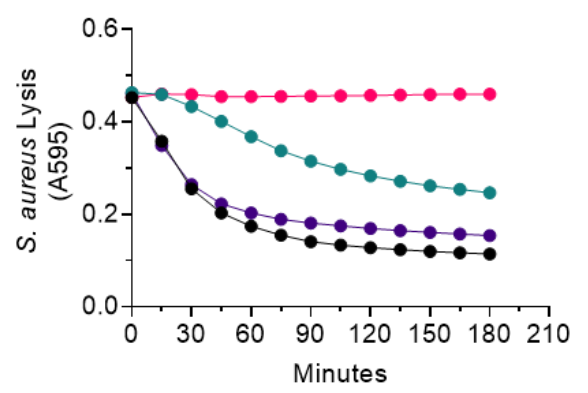

b

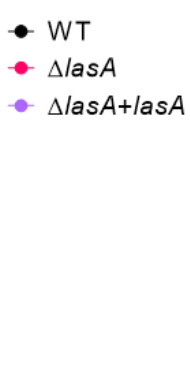

d

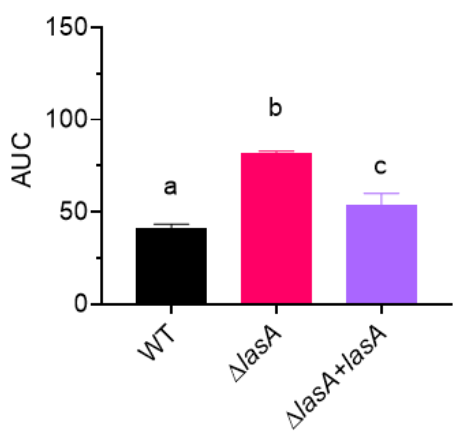

- WT

- WT+TPEN

- $W T+T P E N+Z n$

$-\Delta / a s A$

- WT

- $W T+C P$

- $W T+C P+Z n$

- $\triangle$ las A

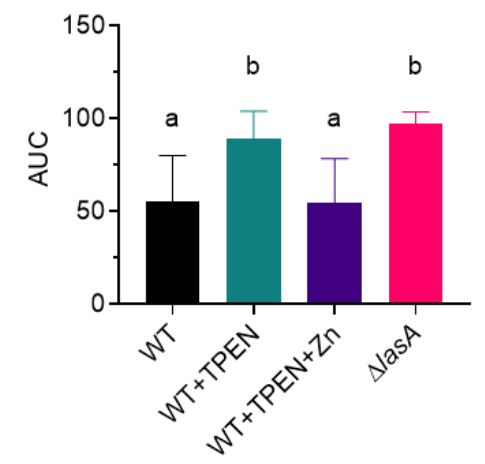

$\mathbf{f}$

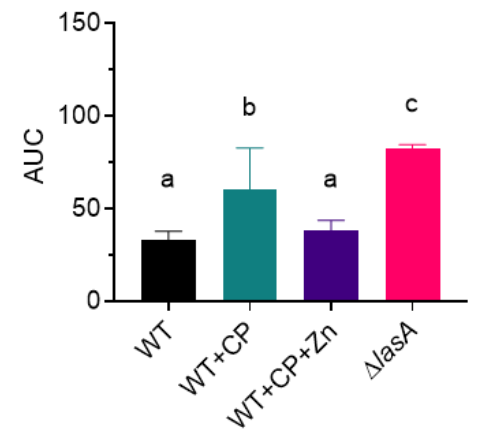

Fig. 5 Zinc chelation inhibits LasA enzymatic activity. (a-b) Lysis of heat-killed $S$. aureus strain $\mathrm{SH} 1000$ by cell-free supernatants from WT, $\Delta$ lasA, and $\Delta / a s A+l a s A$ ( $\Delta$ las $A$ complemented in trans under the Control of arabinose-inducible $P_{B A D}$ ) $16 \mathrm{~h}$ cultures. (c-d) Lysis of heat-killed $S$. aureus strain $\mathrm{SH} 1000$ by WT and $\triangle$ /asA cell-free supernatants. WT supernatant was divided and left untreated (WT), treated with $50 \mu \mathrm{M}$ TPEN (WT+TPEN), or treated with $50 \mu \mathrm{M}$ TPEN and 500 $\mu \mathrm{M} \mathrm{ZnSO}_{4} \cdot 7 \mathrm{H}_{2} \mathrm{O}$ (WT+TPEN+Zn). (e-f) Lysis of heat-killed $S$. aureus strain SH1000 by WT and $\triangle$ las $A$ cell-free supernatants. WT supernatant was divided and left untreated (WT), treated with $40 \mu \mathrm{M}$ CP $(\mathrm{WT}+\mathrm{CP})$, or treated with $40 \mu \mathrm{M} \mathrm{CP}$ and $160 \mu \mathrm{M} \mathrm{ZnSO}_{4} \cdot 7 \mathrm{H}_{2} \mathrm{O}(\mathrm{WT}+\mathrm{CP}+\mathrm{Zn}) .(\mathbf{a}),(\mathbf{c})$, (e) The data represent the mean from three independent experiments. Error bars have been omitted for clarity. (b), (d), (f) Quantification of data in (a), (c), and (e), respectively, using area under the curve (AUC). Data are the mean \pm SD from three independent experiments. The same lowercase letters indicate samples that are not significantly different and different lowercase letters indicate significant differences $(p<0.05)$. 


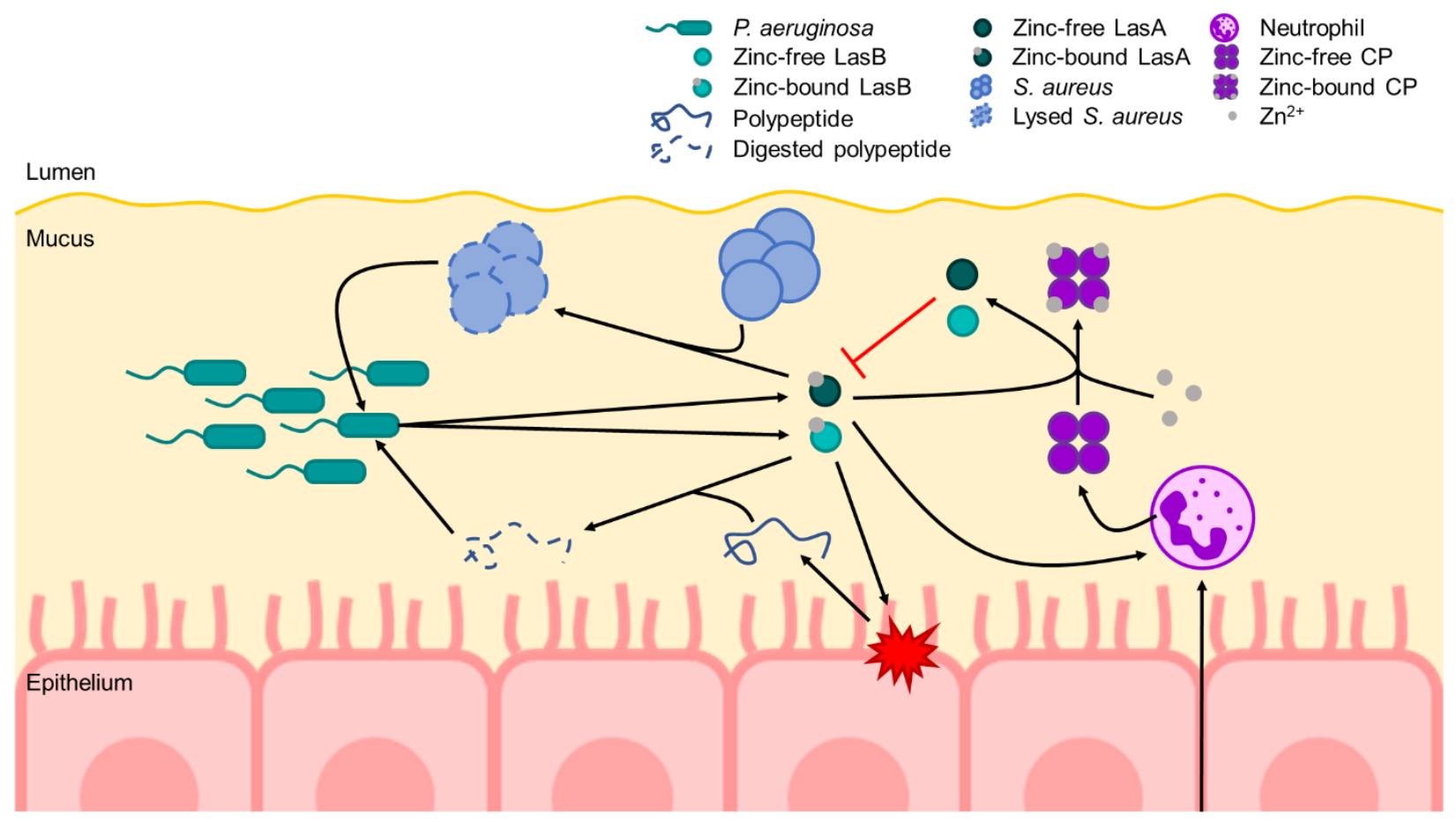

Fig. 6 Model of the effects of CP-mediated zinc chelation in the CF lung on $P$. aeruginosa. $P$. aeruginosa colonizes the mucus in the airways of CF patients to high densities, which in part requires the uptake and utilization of zinc. At high densities, $P$. aeruginosa secretes a variety of quorum sensing-dependent virulence factors including zinc metalloproteases such as LasB and LasA. LasB is a protease that can degrade host proteins, such as elastin, as well as peptides. These degraded proteins/peptides can then be taken up and utilized as nutrients by $P$. aeruginosa. LasA is a protease that lyses $S$. aureus by cleaving pentaglycine bridges of peptidoglycan. LasA-mediated lysis of $S$. aureus allows $P$. aeruginosa to take up nutrients released from lysed $S$. aureus as well as to outcompete $S$. aureus in the CF lung. During infection, neutrophils are recruited to sites of infection/inflammation. Neutrophils may then release cellular contents such as CP. CP can then bind bioavailable zinc away from $P$. aeruginosa thus reducing the overall abundance of $P$. aeruginosa, while also inducing a zinc-starvation response by $P$. aeruginosa. Additionally, CP can bind zinc away from both LasB and LasA thereby inhibiting their proteolytic activity. Furthermore, LasB and LasA activity have been shown to induce neutrophil extracellular traps (NETs). Therefore, CP-mediated inhibition of LasB and LasA activity may lead to less NET formation and, subsequently, less CP release. Black arrows indicate a positive interaction. Red arrows indicate an inhibitory interaction. 